\title{
The effects of contextual factors on dyadic everyday problem solving in adulthood
}

\author{
Tara L. Neely \\ West Virginia University
}

Follow this and additional works at: https://researchrepository.wvu.edu/etd

\section{Recommended Citation}

Neely, Tara L., "The effects of contextual factors on dyadic everyday problem solving in adulthood" (2005). Graduate Theses, Dissertations, and Problem Reports. 2289.

https://researchrepository.wvu.edu/etd/2289

This Thesis is protected by copyright and/or related rights. It has been brought to you by the The Research Repository @ WVU with permission from the rights-holder(s). You are free to use this Thesis in any way that is permitted by the copyright and related rights legislation that applies to your use. For other uses you must obtain permission from the rights-holder(s) directly, unless additional rights are indicated by a Creative Commons license in the record and/ or on the work itself. This Thesis has been accepted for inclusion in WVU Graduate Theses, Dissertations, and Problem Reports collection by an authorized administrator of The Research Repository @ WVU. For more information, please contact researchrepository@mail.wvu.edu. 
The Effects of Contextual Factors on Dyadic Everyday Problem Solving in Adulthood

\author{
Tara L. Neely
}

\begin{abstract}
Thesis submitted to the Eberly College of Arts and Sciences at West Virginia University in partial fulfillment of the requirements

for the degree of
\end{abstract}

\author{
Master of Science \\ in \\ Psychology
}
Jennifer A. Margrett, Ph.D., Chair
Barry Edelstein, Ph.D.
Julie Hicks Patrick, Ph.D.

Department of Psychology

\title{
Morgantown, West Virginia 2005
}

Keywords: adulthood, collaboration, marriage, everyday problem solving,
everyday cognition

Copyright 2005 


\begin{abstract}
The Effects of Contextual Factors on Dyadic Everyday Problem Solving in Adulthood
\end{abstract}

\title{
Tara L. Neely
}

The present study examined individual and dyadic everyday problem solving in 45 younger, middle-aged, and older adult married couples. The goal of the study was to investigate the effects of age, gender, collaboration, marital characteristics, and basic cognition on everyday problemsolving. Two research questions were addressed. First, were there group differences across three phases of problem solving? Second, what was the frequency of individual change, and which factors predicted improvement, stability, or decline? When addressing the first question, there was a significant four-way interaction, $F(4,78)=2.83, p<.05, \eta=.12$, between participant age, gender, problem-solving condition, and problem-solving phase, emphasizing the multidimensionality of everyday cognition. When addressing the second question, a larger percentage of individuals who collaborated reliably improved compared to individuals who worked alone. Furthermore, basic cognitive abilities, education, and marital factors significantly accounted for individual reliable change in everyday problem solving. 


\section{ACKNOWLEDGEMENTS}

I would like to graciously thank all of the members on my thesis committee: Drs. Jennifer A. Margrett, Barry Edelstein, and Julie Hicks Patrick. The valuable guidance and assistance provided throughout the entire development and completion of this project was greatly appreciated. The many contributions made by my mentor, Dr. Jennifer Margrett, were especially helpful and valued. She provided a significant amount of time, monetary contributions, and professional advice, which assisted enormously to the entire course of this study. In addition to her professional support, Dr. Margrett also displayed enthusiasm, encouragement, and interest, which motivated me and aided in developing my passion for research. Every one of her contributions is recognized for truly making this research project possible.

I was fortunate to be surrounded by many ambitious researchers in the area of adulthood and aging at West Virginia University. The last three years have been valuable, and I truly appreciate the knowledgeable and patient faculty who has given their support and encouragement throughout the course of this project. I would like to thank my fellow colleagues, particularly Kristopher Kimbler and Brian Ayotte, who have provided many hours of social support, friendship, and collegial advice. The professional support and encouragement from my colleagues was and still is inspiring, and I am truly grateful for everything.

I would particularly like to thank the Married Adult Teamwork Efforts (MATE) project staff. Petra Reim, Whitney Hudson, Miriah McGinnis, Ron Grace, and Christina Stiltner dedicated many hours to several seemingly endless tasks. Their perseverance was greatly appreciated. In addition, I would also like to thank the married couples who participated in the study and shared their experiences with the team. 
Family and friends have also encouraged me, aided in recruitment, and provided various forms of support in my attainment of this goal, especially my parents K. Bruce and Terri L. Neely and my close friends Christopher Sanner and Meredith McGinley. Everyone's support, enthusiasm, and scholarly excellence will continue to serve as an inspiration in my future endeavors. 
TABLE OF CONTENTS

TITLE PAGE .

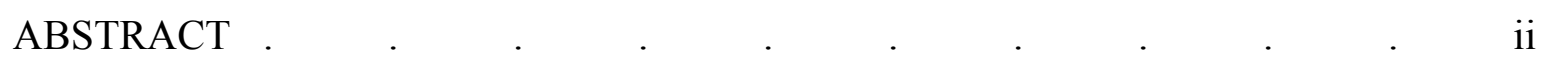

ACKNOWLEDGEMENTS . . . . . . . . . . . . iii

LIST OF TABLES .

LIST OF FIGURES .

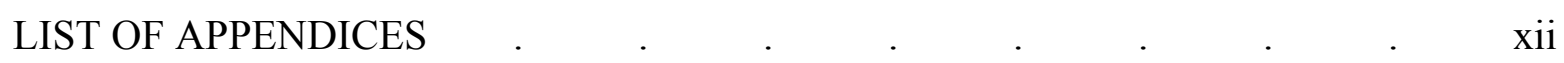

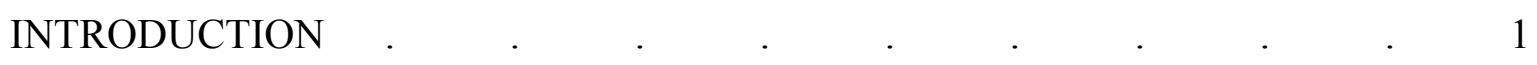

REVIEW OF THE LITERATURE . . . . . . . . . . . . 3

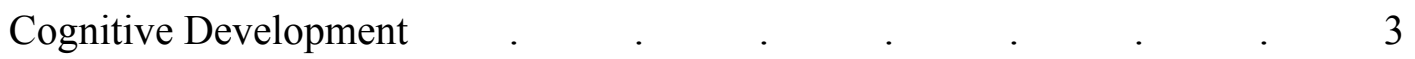

Cognitive Outcomes in Adulthood . . . . . . . $\quad$. 3

Traditional vs. Everyday Cognitive Measures $\quad$. $\quad$. $\quad 5$

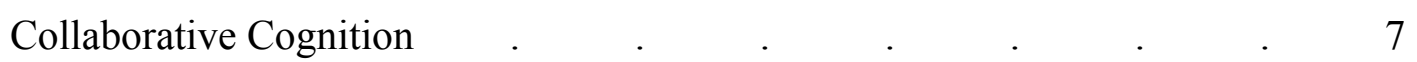

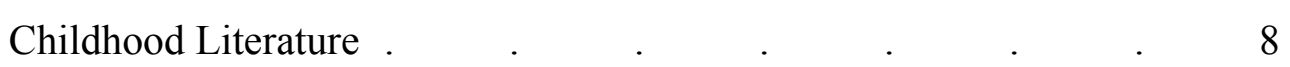

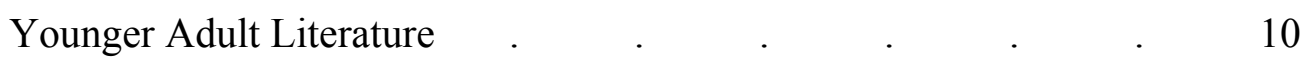

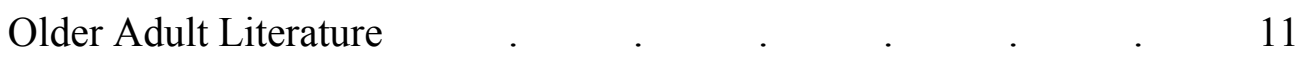

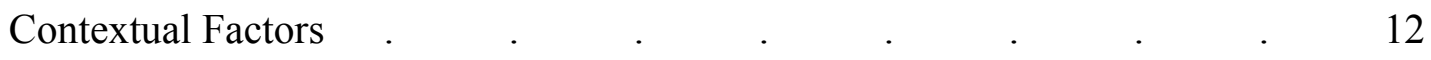

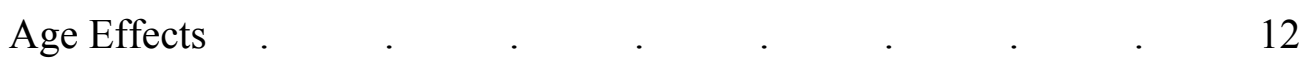

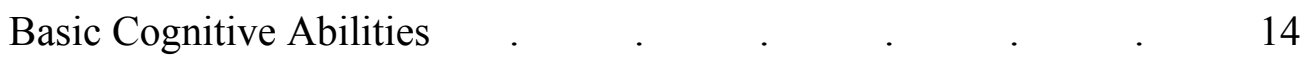

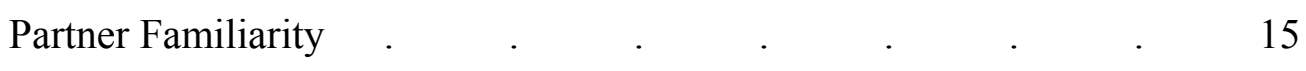

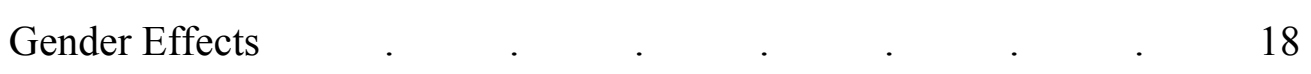

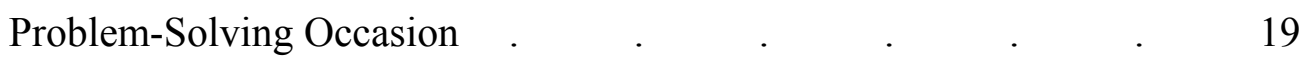

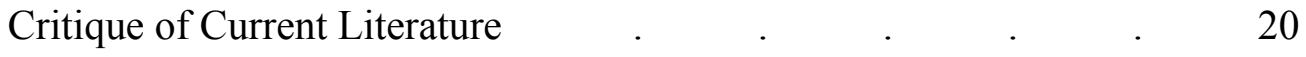




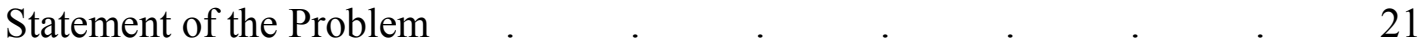

Research Questions and Expected Results . $\quad$. $\quad$. $\quad$. $\quad 22$

RQ1: Group Differences . $\quad$. $\quad . \quad$. $\quad . \quad 23$

RQ2: Individual Change $\quad . \quad \ldots \quad . \quad \ldots \quad$. $\quad . \quad 24$

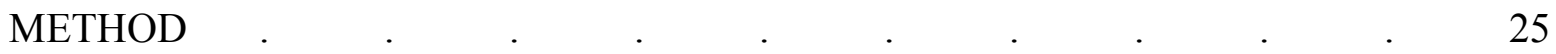

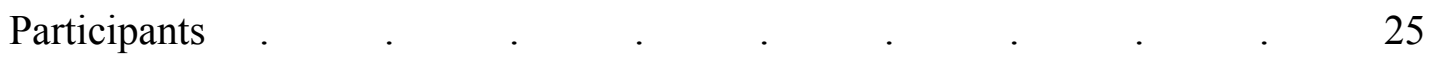

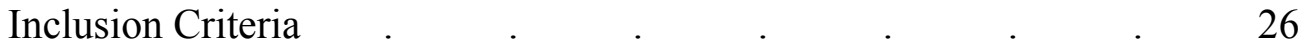

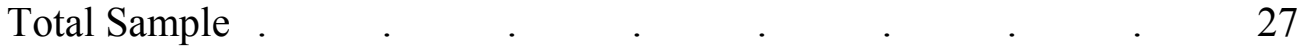

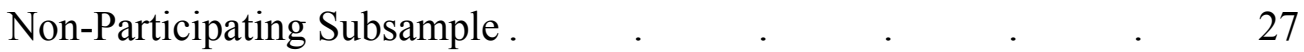

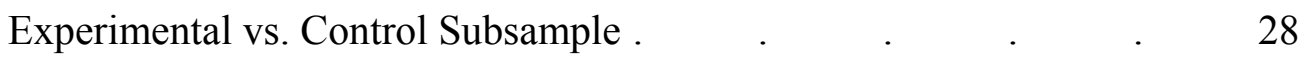

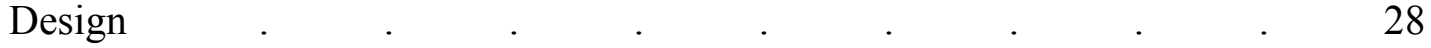

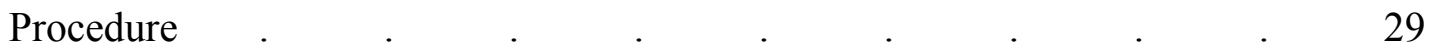

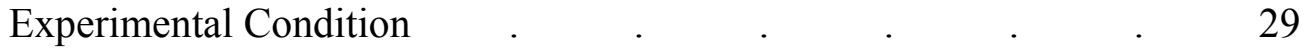

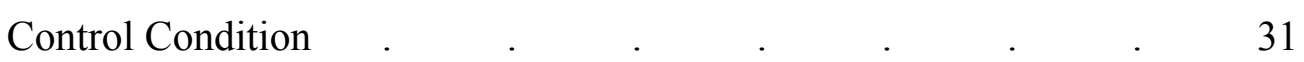

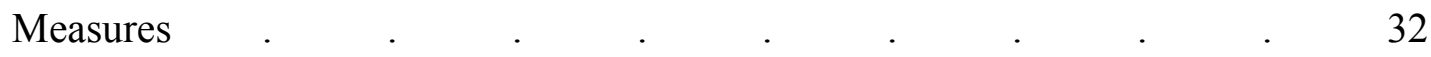

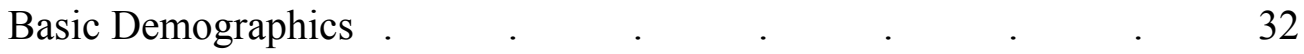

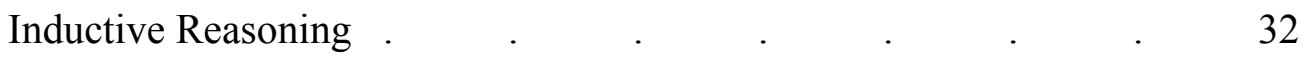

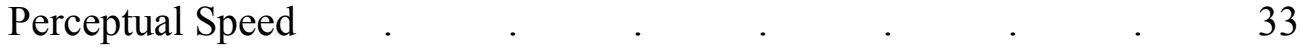

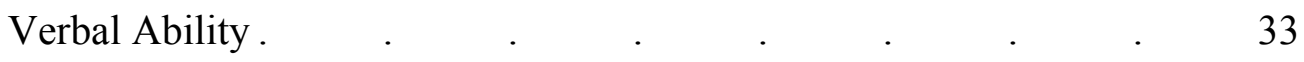

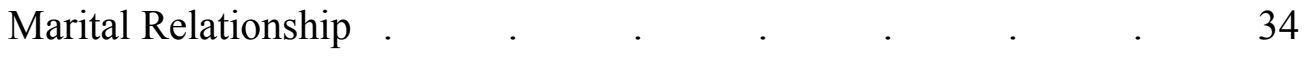

Everyday Problem Solving Inventory $\quad . \quad$. $\quad . \quad$. $\quad . \quad 34$

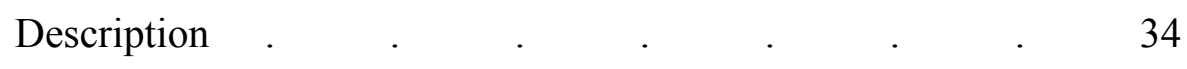

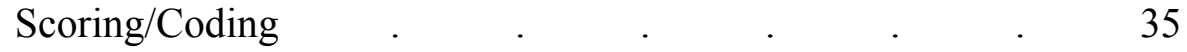




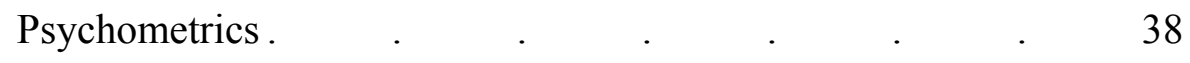

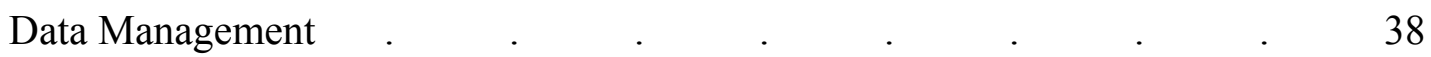

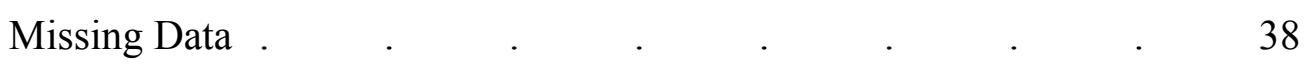

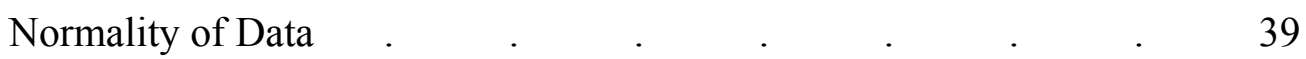

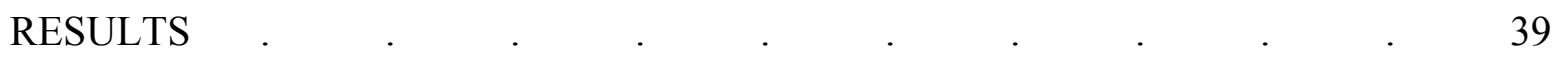

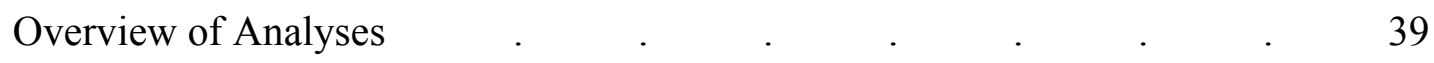

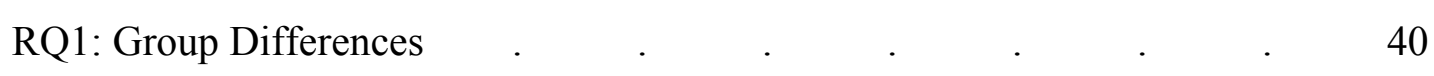

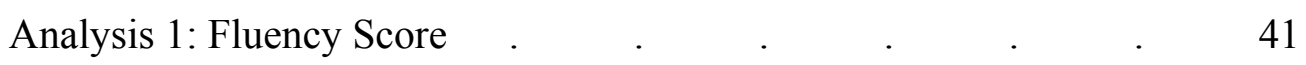

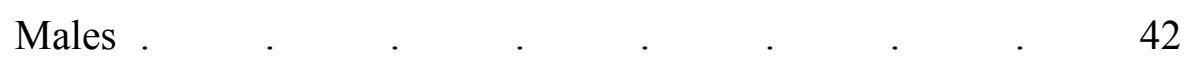

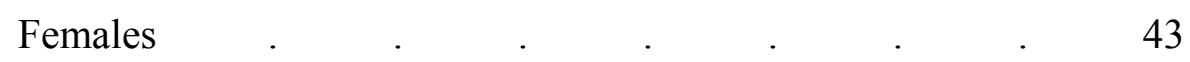

Analysis 2: Efficiency Proportion Score $\quad . \quad$. $\quad . \quad$. $\quad 43$

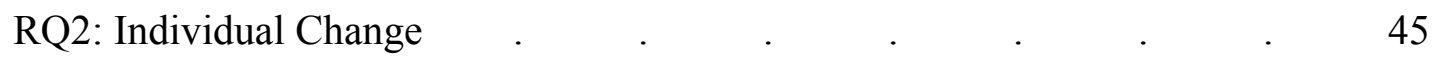

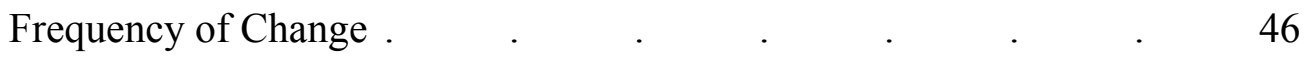

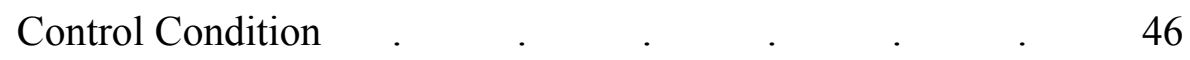

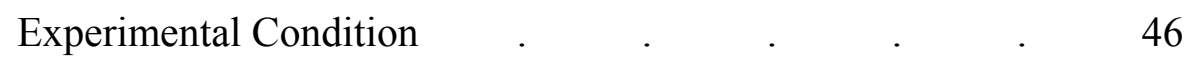

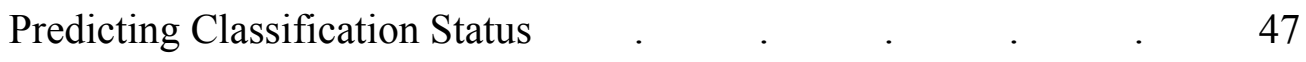

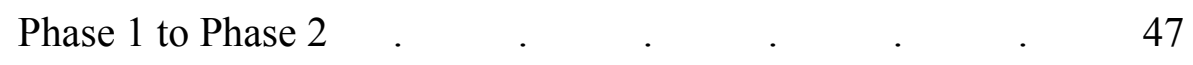

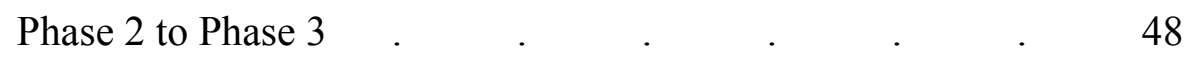

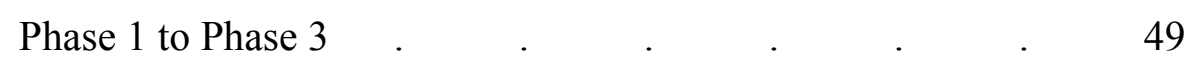

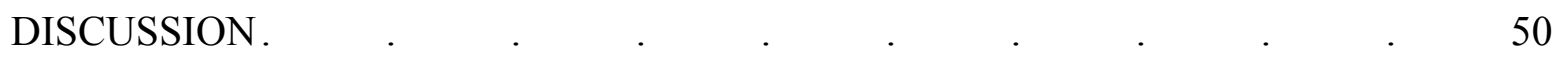

Review of Research Questions and Hypotheses $\quad . \quad$. $\quad . \quad 50$

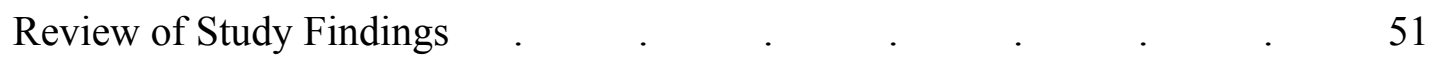

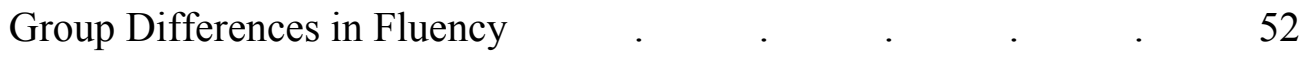




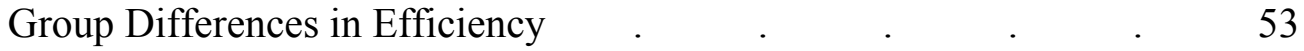

Individual Differences in Fluency $\quad . \quad$. $\quad . \quad$. $\quad . \quad 53$

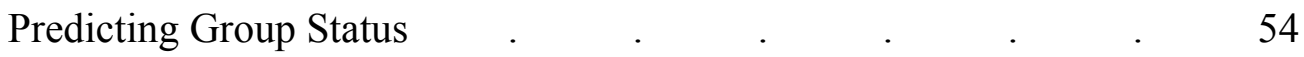

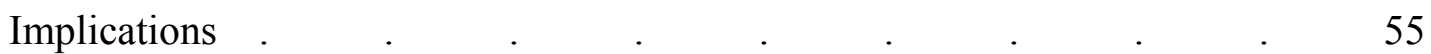

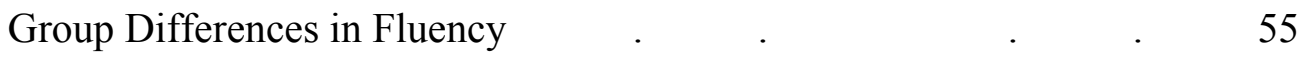

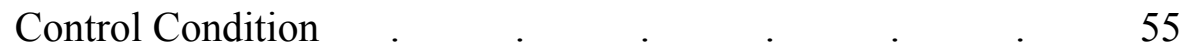

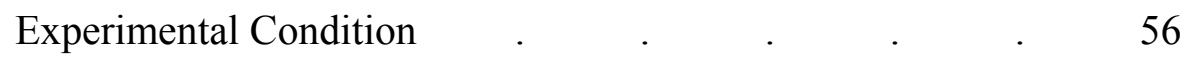

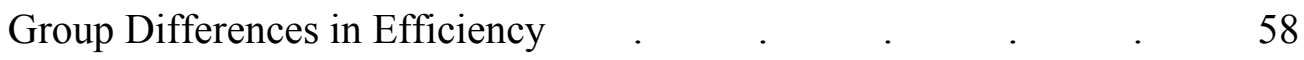

Age Group x Gender Interaction $\quad . \quad$. $\quad . \quad$. 58

Age Group x Problem-Solving Condition Interaction $\quad$. $\quad 59$

$\begin{array}{llllll}\text { Individual Change in Fluency } \quad . \quad & . & . & 6\end{array}$

Predicting Group Status . $\quad . \quad$. $\quad . \quad$. $\quad . \quad 60$

Phase 1 to Phase 2 . $\quad$. $\quad$. $\quad$. $\quad$. $\quad$. $\quad 61$

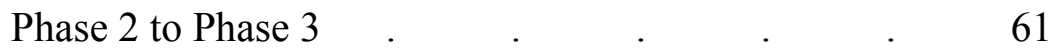

Phase 1 to Phase $3 \quad$. $\quad . \quad$. $\quad . \quad$. $\quad$. 62

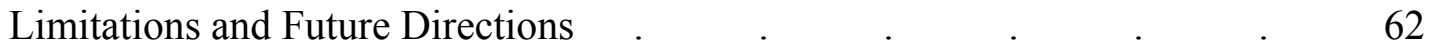

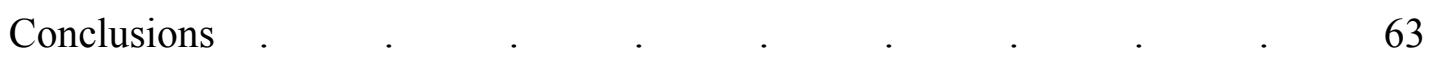

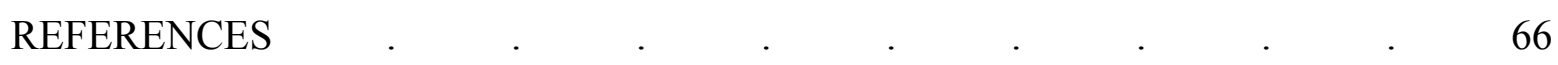

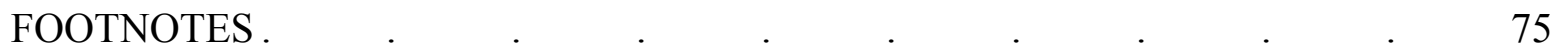




\section{LIST OF TABLES}

1. Descriptive Statistics of Background and Outcome Variables by Age Group $\quad . \quad \ldots \quad$. $\quad . \quad$. $\quad$. 76

2. Subsample Characteristics by Participation Status . . . . . 78

3. Subsample Characteristics by Problem-Solving Condition . . . 79

4. Inter-rater Reliability Checks during

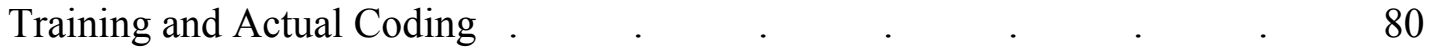

5. Means and Standard Deviations of Younger, Middle-aged, and Older Adults on Problem-Solving Performance Outcome

6. Analysis of Variance Examining Group Differences

$\begin{array}{llllllllll}\text { In Total Safe and Effective Solutions . } & \text {. } & \text {. } & \text {. } & & & 82\end{array}$

7. Analysis of Variance Examining Total Safe and Effective Solutions for Males .

8. Estimated Marginal Means for Gender x Condition $\mathrm{x}$ Age Group x Phase Interaction Examining Total Safe and Effective Solutions .

9. Analysis of Variance Examining Total Safe and Effective Solutions for Females

10. Analysis of Variance Examining Group Differences

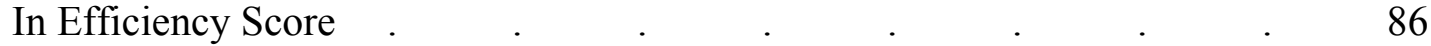

11. Estimated Marginal Means for Gender x Age Group Interaction Examining Efficiency Score

12. Estimated Marginal Means for Condition $\mathrm{x}$ Age Group Interaction Examining Efficiency Score

13. Correlation of Predictor Variables with Discriminant Functions and Standardized Discriminant Function Coefficients for Phase 1 to Phase 2 .

14. Correlation of Predictor Variables with Discriminant Functions and Standardized Discriminant Function Coefficients for Phase 2 to Phase 3 
15. Correlation of Predictor Variables with Discriminant

Functions and Standardized Discriminant Function

Coefficients for Phase 1 to Phase 


\section{LIST OF FIGURES}

1. Depiction of the Experimental (top) and Control Condition (bottom) $\begin{array}{lllllll}\text { Phases with Change Score Calculation } & \text {. } & \text {. } & \text {. } & & 92\end{array}$

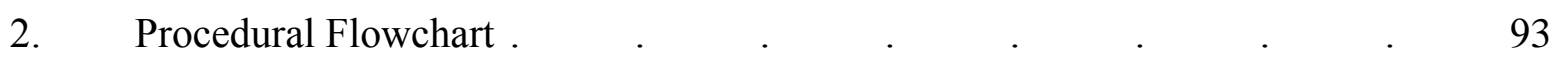

3. Problem-Solving Phase x Gender x Problem-solving Condition x Age Group Analysis of Variance for

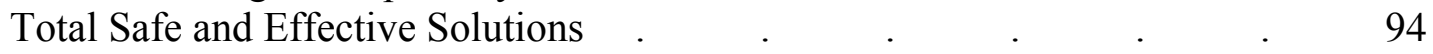

4. Gender x Age Group Interaction for Efficiency

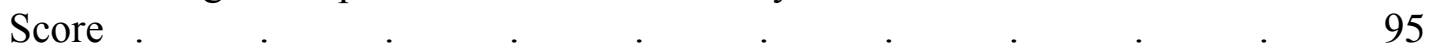

5. Problem-solving Condition x Age Group Interaction

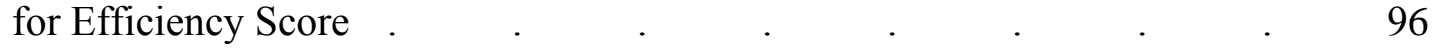

6. Frequencies of Reliable Change for Phase 1-2, Phase 2-3, and Phase 1-3 . . . . . . 97 


\section{LIST OF APPENDICES}

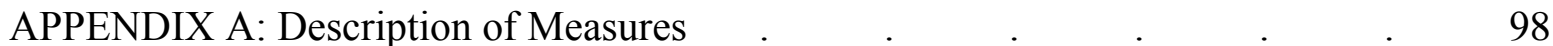

APPENDIX B: Everyday Problem Solving Inventory Items

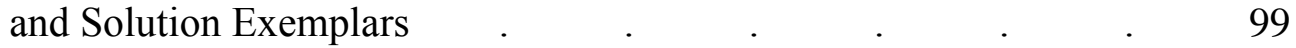

APPENDIX C: Everyday Problem Solving Inventory

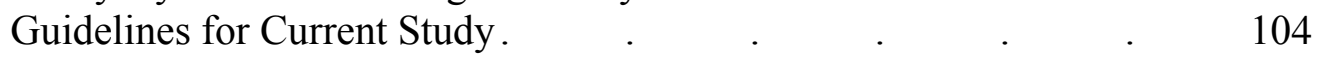




\section{Introduction}

An intriguing question related to the study of cognition is the extent to which collaborative cognition, or working with social partners on a task, enhances everyday competence. A central issue is the extent to which individual characteristics (e.g., age, gender, cognitive ability), dyadic characteristics (e.g., partner familiarity, length of relationship, marital quality), and design factors (e.g., task, scoring methods) affect collaborative everyday problemsolving performance (Margrett \& Marsiske, 2005). Examining the influence of these factors on collaboration and everyday problem solving is either unknown or findings are inconsistent in the current literature (Margrett \& Marsiske, 2005; Thornton \& Dumke, 2005).

The inconsistency in the extant literature may be due to the fact that few studies examined how individual, dyadic, or design factors influence collaborative or everyday problemsolving outcome in adulthood (e.g., Margrett, 1999; Margrett \& Marsiske, 2005). A consideration of contextual factors is important because it could provide additional insight to the field of social cognition in several ways. First, exploring differences between males and females would help researchers better understand who improves in performance as a result of the collaborative experience or who might perform better on certain types of everyday tasks (Margrett \& Marsiske, 2002). Second, addressing how ability level relates to collaborative performance may help certain individuals (e.g. lower functioning) approach problems more successfully in daily life. If individuals with lower abilities are able to perform better with a partner on everyday tasks, collaboration should be emphasized as a means of cognitive maintenance. It would also be important to show additional evidence for which basic cognitive abilities (e.g., inductive reasoning, perceptual speed, verbal ability) relate to everyday problemsolving outcome (Allaire \& Marsiske, 1999). Third, one's perception of the quality of their 
relationship or the length of one's relationship may help clarify what encompasses partner or "couples' expertise" because it is currently unknown what particular characteristics lead to the development of the knowledge about one's significant other (Carstensen, Levenson, \& Gottman, 1995; Dixon \& Gould, 1996, 1998). Fourth, addressing age differences in collaborative performance may foster the use of partners in cognitive training and intervention programs. Implementing collaborative cognition programs may result in enhanced cognitive performance or retention of cognitive skills in an aging population (Margrett \& Willis, in press).

Prior literature clearly illustrates that collaborative everyday cognition relies heavily on a complex interplay between several contextual factors (Margrett \& Marsiske, 2005). Unfortunately, several of these factors have received only minimal attention in the extant literature. Therefore, the current study investigated the extent to which individual, dyadic, and design characteristics affect collaborative everyday cognition on problems frequently encountered in adulthood.

The everyday cognition and the collaborative cognition literatures are reviewed for the current study. The first section of this paper highlights cognitive changes in adulthood in terms of which areas of cognition appear to decline, remain stable, or improve with chronological age. Within this section, there is a discussion of the theoretical importance of examining everyday cognitive measures as opposed to traditional cognitive measures. Age differences found in performance on everyday problem-solving tasks are also addressed. Finally, a discussion of collaborative cognition and contextual factors related to collaborative everyday problem-solving performance is presented. 


\section{Cognitive Development}

\section{Cognitive Outcomes in Adulthood}

Cognitive aging, the study of cognition throughout adulthood, continues to be a growing area of interest in human development, particularly in terms of how older adults can maintain independence and functioning in later life. Life expectancy is increasing; thus cognitive aging is receiving more attention in gerontological research than in the past. Support for cognitive age differences and declines (e.g., Allaire \& Marsiske, 1999; Salthouse, 1996; Salthouse \& Babcock, 1991; Schaie, 1989a, 1989b, 1993) as well as support for compensatory behaviors utilized in older adulthood (e.g., Dixon \& Bäckman, 1995; Freund \& Baltes, 1998, 2002) has accrued.

Throughout the Seattle Longitudinal Study, Schaie and his colleagues assessed a variety of primary mental abilities (i.e., verbal meaning, number skill, inductive reasoning, spatial abilities, and word fluency) that demonstrated individual differences in performance across age groups (Schaie, 1989b, 1993). Accumulated data regarding changes in mental abilities across time indicate that fluid abilities (process-based abilities) decline sooner than crystallized abilities (knowledge-based abilities). For example, fluid abilities such as reasoning, speed, and fluency tend to decline in adulthood, whereas crystallized abilities such as vocabulary and reading comprehension remain stable and may even increase slightly into adulthood. Furthermore, gradual decline in most abilities begins at age 60 years, but it is not until the age of 74 years that greater age decrements are detected in basic mental abilities. Overall, research indicates that the course of cognitive aging is based largely on the types of abilities measured (e.g., basic vs. everyday; Schaie \& Willis, 1999) as well as individual characteristics (e.g., education, health; Diehl, Willis, \& Schaie, 1995; Schaie, 2000), and environmental circumstances (socioeconomic status; Schaie, 2000; social support; Schaie \& Willis, 1999). 
As a result of the findings documenting cognitive decline in older adulthood, a number of developmental studies examined how some aspects of cognition can be retained or enhanced through intervention (e.g., Ball et al., 2002; Margrett \& Willis, in press), and how older adults may compensate for cognitive losses (Dixon \& Bäckman, 1995; Freund \& Baltes, 1998, 2002) in later adulthood. Empirical studies that focus on successful aging increased due to the interest in possible approaches to buffer against cognitive decline and to promote cognitive maintenance. Some of the mechanisms thought to increase cognitive maintenance are interventions (e.g., practice and/or training in basic cognitive tasks; Ball et al., 2002; Denney \& Heidrich, 1990; Margrett \& Willis, in press), social environment (e.g., the presence of a collaborative partner; Dixon \& Gould, 1996, 1998; Margrett \& Marsiske, 2005), and deliberate efforts and personal activities (e.g., internal and external memory aids, selecting goals; Bäckman \& Dixon, 1992; Dixon \& Bäckman, 1995).

Understanding cognitive loss, maintenance, and gain has several important implications for developmental research and society (e.g., Baltes, 1993). In terms of developmental research, a clearer understanding of cognition can direct the focus of science to the areas that greatly affect cognitive change (e.g., individual differences, training, prevention). Implications for society include issues relevant to events older adults face later in life (e.g., retirement, changes in independence, well-being). Also, it is important for society to understand and promote competency due to a rapidly growing older adult population. To increase this understanding, researchers need to focus not only on basic cognitive performance, but also concentrate on common, everyday cognitive performance. 


\section{Traditional vs. Everyday Cognitive Measures}

Promoting the maintenance of cognitive abilities and competency in adulthood requires a thorough understanding of cognitive performance and functioning. Therefore, it is necessary to explore the link between measures of basic and everyday cognitive abilities. To do so, a clear definition of everyday problem solving is needed. Thornton and Dumke (2005) state that current studies in the everyday cognition literature lack a clear definition of everyday problem solving. Through an examination of several studies, Thornton and Dumke adopt the definition of everyday problem solving as completing tasks relevant to an issue that may commonly occur in life and the task requires an individual to generate solutions or make decisions to obtain a desired result. The current study also adopts this definition.

The theoretical importance of studying the outcomes of individuals on everyday cognitive measures as opposed to basic traditional measures relies on the fact that most issues encountered in daily life rely largely on reasoning about problems, making decisions, and imposing judgments (Meegan \& Berg, 2002). These situations are especially applicable to adults who are faced with many social circumstances that rely on everyday thinking abilities. Allaire and Marsiske (1999) found that basic cognitive performance was related to performance on everyday measures, yet whether basic cognition reliably predicts everyday problem solving is not entirely conclusive. In other words, basic abilities may not be the most accurate indicators of how individuals approach problems encountered in their daily lives (Heidrich \& Denney, 1994).

Heidrich and Denney (1994) found that everyday cognitive measures assessing social or practical problem solving were more predictive of older adults' everyday functioning than were traditional cognitive measures. This finding may be due to the cumulative experience of interacting with other people and accumulated knowledge of routine everyday tasks that older 
adults face throughout a lifetime (Baltes, 1993). In Heidrich and Denney's study, younger (18-39 years) middle-aged (40-59 years), and older (60-85 years) adults performed a variety of tasks consisting of social, practical, and traditional problem-solving components. Although younger adults outperformed older adults on traditional measures, younger and older adults performed similarly on the social and practical problem-solving tasks. Also, middle-aged adults performed slightly better than younger and older adults. Therefore, it appears that the use of realistic stimuli facilitated older adults' performance and eliminated age differences that are typically found in traditional problem-solving tasks.

According to Allaire and Marsiske (1999), everyday cognitive performance may be predicted from traditional cognitive measures that assess basic cognitive abilities. In their study, Allaire and Marsiske developed a new battery of everyday cognitive measures, which included three areas of daily functioning (i.e., food preparation, medication use, and financial planning). The goal was to assess the relation between everyday cognitive measures and traditional psychometric tests, which included measures of declarative memory, inductive reasoning, and knowledge. Basic abilities were significantly correlated with performance on these everyday cognitive tasks, suggesting that basic cognitive abilities underlie everyday task performance.

In summary, there appears to be two theoretical approaches to understanding age differences in everyday cognition (Marsiske \& Willis, 1995; Thornton \& Dumke, 2005). Some research suggests that basic cognitive abilities relate to everyday abilities (Allaire \& Marsiske, 1999). Therefore, if basic abilities tend to decline in older adulthood (e.g., Schaie, 1993), then a similar pattern may be found in everyday problem solving; thus resulting in age differences in performance. The other theoretical approach posits that through experience and accumulated knowledge, everyday problem solving could be preserved or even improved into late adulthood; 
thus minimizing or eliminating age differences (e.g., Baltes, 1993; Cornelius \& Caspi, 1987;

Heidrich \& Denney, 1994). Therefore, rather than focusing on declines in basic abilities, assessing practical or social problem solving may be a more accurate indicator of everyday competence in adulthood. In addition, working with a partner may also affect age differences on problem-solving outcome, particularly in the area of everyday competence. It is suggested that dyadic collaboration on everyday tasks may provide the opportunity for an important and unique evaluation of everyday cognitive performance.

\section{Collaborative Cognition}

Previous investigations of collaborative cognition (i.e., individuals working together to solve problems) led to improved understanding of certain aspects of cognitive development across the lifespan. The collaborative cognition literature suggests that not only do persons of all ages participate in collaboration, but they also benefit cognitively and socially when working with other people to solve problems. Theorists such as Vygotsky (1978) stated that because collaborative cognition occurs regularly in many environments such as family, work, and school, it is developmentally significant. In other words, collaborative cognition plays an important role in our daily lives beginning at an early age and continues to be important throughout the lifespan. Since Vygotsky's seminal work the extent to which collaboration possesses practical implications or functional relevancy across age groups was investigated prominently within the child development literature. It is very likely that Vygotsky's principles and the findings in the childhood collaborative cognition literature contributed to the focus on adult collaborative cognition. Therefore, the childhood literature warrants a review. 


\section{Childhood Literature}

The majority of developmental research pertaining to collaborative cognition examines older children (e.g., school-aged) working with more experienced partners. Lev Vygotsky and Jean Piaget pioneered this area of collaboration and cognitive research by advocating the social context as an important aspect of individual cognitive functioning for developing children. Aspects of both theories may be applied to collaborative cognition at later stages of development as well.

Classic research by Vygotsky (e.g., 1978) suggests that verbal exchanges occurring during collaboration between individuals begin as external speech, which then becomes internalized over time. The "zone of proximal development" is a well-known component of Vygotsky's theory. The zone of proximal development is the difference between a child's ability to individually solve problems and the level attained when collaborating with more advanced partners. Hence, the zone of proximal development is the child's potential to reach his or her maximum performance on a task. Scaffolding, or guided participation, is the technique used in Vygotsky's (1978) theory of zone of proximal development to enhance cognition and reach higher levels of performance. Scaffolding usually occurs between an individual and a more experienced partner (e.g., a parent, a teacher, or a tutor), which boosts the individual's execution on a task (Rogoff, 1998). Typically, the greater-skilled individual intensifies the lesser-skilled individual's interest and reduces the number of steps required to complete the task. Although Vygotsky's theory is typically applied to childhood, similar principles (e.g., individual and partner ability) could relate to collaborative cognition in adulthood as well.

Piaget's model of constructivism proved to be crucial for classroom-based peer learning, despite the main focus on individual cognition. According to Piaget, constructivism refers to the 
ability of an individual to process and organize experiences in the environment to maintain a sense of order and successfully adapt to surroundings (De Lisi \& Golbeck, 1999). Therefore, the way a child organizes a given classroom environmental context (i.e., meaning making, assimilation, or accommodation) might occur differently in the presence of other students as opposed to working alone. By allowing peer interactions in the classroom, Piaget believed students would be given the ability to evaluate and revise their own personal cognitive mechanisms by building on the ideas of others (De Lisi \& Golbeck, 1999). Perhaps adults could also build on the ideas of others through collaboration and subsequently improve their own individual problem-solving performance.

In more recent childhood literature, positive effects of collaborative cognition on performance were found (e.g., Golbeck, 1998; Hart, 1993; Fleming \& Alexander, 2001), and some studies examined factors that affected collaborative outcome. Watson and Chick (2001) assessed factors in relation to improvement, stability, or decline in cognitive functioning. They found that individual cognitive factors (e.g., previous experience, cognitive ability), interpersonal factors (e.g., leadership, social collaboration), as well as external stimuli in the environment (e.g., task) influenced collaborative outcome on open-ended mathematical tests. These findings illustrated the complexity between several factors and collaborative outcome.

Tudge and Winterhoff (1993) examined how partner competency affected collaborative outcome. They found that 5- and 6-year-olds gained more from collaborative interaction when working with a more competent partner than when working alone or with an equally capable partner. Additionally, Garton and Pratt (2001) examined 4- and 7-year-old children working together on card-sorting tasks. When working with a higher-skilled individual, the less-skilled child's individual problem solving was facilitated. Furthermore, these individuals performed 
better relative to those who worked alone or with a similar-ability partner. Although collaboration tends to be beneficial for a less-skilled partner, effects may not be seen for children who work with less-experienced partners (Garton \& Pratt, 2001) or for those who work with opposite-sex partners (Light, Little, Bale, Joiner, \& Messer, 2000). Most researchers, however, would support the idea that when working individually, children will not experience the same quality of development in thinking and problem solving that collaboration facilitates (Gauvain \& Rogoff, 1989).

\section{Younger Adult Literature}

As previously noted, collaborative cognition research focuses primarily on child development; however, a few researchers examined the mechanisms underlying the functions of collaboration in young adulthood. The majority of studies that involve younger adults are comparative in nature. Specifically, younger adults' collaborative problem-solving performance is usually compared to that of older adults, resulting in few studies that solely focus on collaborating younger adults. The comparative findings of younger versus older adult collaborative performance will be mentioned in a subsequent section.

The literature that examines collaborating younger adults primarily targets college-aged individuals, and the tasks tend to focus on communicating via computers (e.g., Ocker \& Yaverbaum, 1999; Stoyanova \& Kommers, 2002) or completing scientific coursework (e.g., Chinn, Mãnoa, \& Hilgers, 2000; Scanlon, 2000). Stoyanova and Kommers (2002), for instance, examined how concept mapping affected learning outcome when collaborating on a computersupported problem. This study was conducted with university students as participants, and they found that shared cognition with the computer-supported program was an effective mechanism 
for computer-based problem solving because it boosted individual cognitive performance (i.e., developing a multi-media item).

\section{Older Adult Literature}

As mentioned previously, the young adulthood collaborative literature is limited, unless younger adults are compared to different age groups. This tendency to compare is likely due to the growing interest in collaboration as an effective tool for successful cognitive aging in older adulthood research. Terms such as shared knowledge, collective minds, collaborative cognition, and interactive minds are appearing at a greater frequency in the gerontological literature (e.g., Staudinger \& Baltes, 1996; Strough \& Margrett, 2002). According to Staudinger and Baltes (1996), these phrases refer to circumstances when individuals are actively engaged in collaboration (external), as well as situations involving individual perception about the presence of another person to assist in solving problems (internal). An increase in the use of these terms may be due to the fact that most everyday cognitive activity occurs in a context with other people. For example, collaborative cognition occurs when spouses plan vacations, decide on supplemental health insurance, argue about household responsibilities (Meegan \& Berg, 2002), retell stories to others (Dixon \& Gould, 1998), or solve interpersonal problems (Margrett \& Marsiske, 2002). Therefore, it is logical to study adulthood cognition not only as an individual phenomenon but also as a social endeavor.

Previous studies that examined cognition as a social endeavor asked participants to collaborate on a variety of tasks such as wisdom advice giving (Staudinger \& Baltes, 1996), prose recall and retelling stories (Dixon \& Gould, 1998, 1996), as well as errand planning and resolving hypothetical social dilemmas (Margrett \& Marsiske, 2002). Under most circumstances, collaboration improved performance for younger and older participants, but note that a complex 
interaction of factors was present in the findings. This complexity is particularly evident in the work by Margrett and Marsiske (1999, 2002, 2005) who examined the effects of several contextual factors on collaborative everyday problem solving in older adults. Potential contextual factors that influence cognitive collaboration performance are discussed below.

\section{Contextual Factors Affecting Collaborative Everyday Cognition}

Current literature suggests that collaboration is generally beneficial to adults, but there is only minimal attention paid to the role that specific contextual factors play in collaborative performance. The current study addressed several specific factors (i.e., age, gender, marital length, marital quality, cognitive ability, and problem-solving occasion) that may relate to collaborative everyday problem-solving outcome. Age Effects

One reason for examining contextual factors in the current study is that they may be operating in collaborative and/or everyday problem-solving circumstances, and thus mask or intensify age differences (Thornton \& Dumke, 2005). For example, the type of scoring may affect age differences because older adults tend to provide less detail about responses and focus more on quality answers (Gould, Trevithick, \& Dixon, 1991). Therefore, age differences may be intensified on precision or fluency assessments but minimized on assessments that focus on quality responses. A deeper understanding of contextual factors would not only lead to a clearer interpretation of everyday problem-solving outcome, but it would also lead to a better understanding of age comparisons.

Based on collaborative cognition studies that examined age differences between younger and older adults, both age groups typically benefit from collaboration. Benefit from collaboration is defined as the group outcome on a task being better compared to individual problem-solving 
outcome. When older adult averages on a collaborative task are compared to younger adult averages, older adult performance is typically lower, despite the fact that collaboration was beneficial. Perhaps collaboration may be a means of cognitive enhancement for younger adults, yet a compensatory technique for cognitive decline in older adults (Margrett \& Marsiske, 2002; Strough \& Margrett, 2002).

Staudinger \& Baltes (1996) found that when older adults used "external dialogue" (i.e., conversation between at least two people), along with "individual thinking time" (i.e., using mental representations of other people), older adults gained more from this technique than younger adults. This form of collaboration was found to facilitate cognitive performance to a higher degree in older adults compared to younger adults, despite the fact that younger adults outperformed older adults.

Dixon, Gould, and their colleagues utilized designs in which participants (younger and older adults) were required to retell stories (i.e., prose recall). Gould, Trevithick, and Dixon (1991) found that the quantity of information recalled by younger and older adults was similar; however the quality of the responses during prose recall differed between younger and older adults. Similarly, Gould, Osborne, Krein, and Mortenson (2002) found that older adults focused on recalling more main ideas than specific details from a story. Besides examining age differences in outcome, Dixon and Gould (1998) also examined whether individuals who collaborated on a story recall task lessened basic ability decline associated with older age. Participants assigned to the individual, dyad, or tetrad condition, were exposed to two narratives depicting the start of a new career and managing a financial problem in the family. Collaborative text recall of the recently heard prose, when measured against individual performance, demonstrated better outcomes. Additionally, younger and older adults both benefited equally 
from collaboration and performed with greater accuracy with more collaborators (i.e., tetrad vs. dyad). A review of age comparisons in the collaboration literature suggests that context interacts with age to influence collaborative problem-solving performance.

\section{Basic Cognitive Abilities}

Related to age differences is individual basic cognitive performance, which may be another indicator of everyday problem-solving outcome. Several studies found that individual everyday problem-solving ability relates to basic cognitive abilities (e.g., Allaire \& Marsiske, 1999; Cornelius \& Caspi, 1987; Diehl, et al., 1995; Margrett, 1999). Most relevant to the current study is the findings of Cornelius and Caspi (1987). These researchers designed the everyday problem-solving assessment that was used in the current study (Everyday Problem Solving Inventory, EPSI). This measure was administered to participants aged 20-78 years. They found that performance on the EPSI was significantly correlated with traditional measures of cognition, including verbal $(r=.27)$ and inductive reasoning abilities $(r=.29)$, yet older adults outperformed younger adults.

More recently, Allaire and Marsiske (1999) administered several basic cognitive ability tests such as measures of inductive reasoning, perceptual speed, verbal ability, domain specific knowledge, and working memory. They correlated these basic ability outcomes with everyday cognition measures. Each everyday measure (e.g., finding patterns in printed materials, everyday text recognition) was strongly and positively related to the assessments of basic cognition. Traditional and everyday measures were also related to the age of the participant. The findings of this study suggest that everyday problem solving relates to traditional problem solving and is sensitive to age differences. The limitation of this particular study is that the everyday 
assessments did not include any complex social or emotional problems, nor did they include domains of an interpersonal nature.

Margrett (1999) examined the relation between several measures of basic abilities to three tasks of everyday problem solving, which involved solving everyday printed materials as well as solving hypothetical social dilemmas (e.g., a social task). She found that all basic cognitive abilities were moderately but significantly related to everyday problem-solving outcome; however the magnitude of the relation was lower compared to previous studies. Based on the findings relating basic cognition to everyday cognition, the current study examined how basic abilities predict everyday performance change across three occasions.

\section{Partner Familiarity}

The type of partner an individual works with during collaboration may also influence collaborative outcome. The majority of the collaborative cognition literature suggests that working with a familiar partner is useful. Dixon, Gould, and colleagues (e.g., 1991, 1994, 2002) demonstrated that unfamiliar partners were less focused on a collaborative task due to off-task interactions. Similarly, Kimbler and Margrett (2005b) found that unfamiliar partners demonstrated a higher proportion of task irrelevance compared to familiar partners. Due to the time spent getting to know each other and sharing experiences during the task, prose recall and everyday problem solving performance was hindered.

Andersson and Rönnberg $(1995,1996)$ also found that collaboration could impose costs on memory performance when working with a familiar partner (i.e., friends). These studies indicated that recall in the collaborative situation was less compared to pooled individual performances. This finding could be partially due to the fact that knowing someone may lead to time spent coordinating tasks during the collaborative situation. These studies also focused on 
collaborating friends rather than spouses and also examined outcome on traditional rather than everyday problem-solving tasks.

Despite these contradictory findings, collaboration tends to boost everyday problemsolving performance, particularly when working with a significant other or romantic partner (Gould et al., 2002; Gould, Kurzman, \& Dixon, 1994; Gould et al., 1991, Margrett \& Marsiske, 2002). Although the majority of studies examined collaborating married couples, few studies actually examined collaborative everyday cognition within marriages of varied durations. Whether or not marital duration affects problem-solving outcome leads to the question as to when couples actually develop cognitive interdependency (Rusbult, Arriaga, \& Agnew, 2001) or “couples' expertise" (Carstensen et al., 1995; Dixon \& Gould, 1996, 1998). If the duration of marriage determines relationship expertise, then age could be a potential confound to dyadic experience with a spouse. Dixon \& Gould (1998), however, found that younger and older adults, despite the differing lengths of relationships, possessed a similar level of expertise and familiarity with each other. Development of "couples' expertise" (i.e., awareness of partner characteristics, feelings, and perceptions; Margrett \& Marsiske, 2005) may strengthen spousal roles and facilitate communication in the marriage, and consequently aid in collaborative cognition tasks (Gould et al., 1991).

Perhaps an explanation for differences in everyday problem-solving outcome is due to the process of collaboration occurring between younger and older married couples. Berg, Johnson, Meegan, and Strough (2003) investigated the importance of verbal interactions between younger and older married couples on everyday cognitive tasks. The majority of the married couples used shared decision-making and cooperation during a collaborative task. Couples also expressed the importance of dividing household labor and designating daily collaborative acts. Findings 
suggested that although the majority of the couples collaborated successfully, there exists diversity in the patterns of collaboration and how each couple approaches everyday problems when completing a task. Interestingly, Berg and colleagues also found that younger and older couples did not differ in how they interacted with regard to their communication styles. Specifically, no age differences were found in either low or high affiliation exchanges or in the different patterns of speech acts during collaboration. This finding contradicts the theory that long-term marriages, characterized by lower conflict, would result in lesser amounts of low affiliation for older adult couples (Carstensen et al., 1995).

The mixed findings described in previous literature suggest that thorough examination of everyday collaboration among married couples is necessary. Another reason to study married couples is due to the fact that with increasing chronological age, married couples are the most prevalent naturally occurring dyad. For example, statistics from the 2001 US Census Bureau illustrated that the majority of women aged 25-29 years and older and men aged 30-34 years and older had married at lease once. Specifically, $69.1 \%$ of men over the age of 15 years and $75.4 \%$ of women over the age of 15 years had married. Furthermore, almost $97 \%$ of adults over the age of 70 had married at least once. Due to the fact that the majority of individuals eventually marry, spouses have a greater likelihood of sharing problems compared to other dyads (e.g., coworkers, neighbors, or other family members). The concept of "couples' expertise" requires further exploration in the literature in terms of its relationship to age, length of marriage, and relationship quality. The focus of married couples in the current study, allows for the investigation of "couples' expertise", duration of relationship, length of marriage, and marital quality and whether they can be predictive of collaborative gain. 


\section{Gender Effects}

Studies also suggest that gender relates to collaborative outcome. For example, Margrett \& Marsiske (2002) examined whether or not males and females were equally influential in determining the dyadic collaborative outcome on various tasks. Males were more influential during less-structured tasks (assessments with multiple correct answers), but females earned higher scores. Males and females did not significantly differ in influence or problem-solving outcome when collaborating on well-structured tasks (assessments with one correct answer). Therefore, when the task could be interpreted as ambiguous, such as solving social dilemmas, males had more of an impact regarding the collaborative outcome of the task, but as individuals, females performed better. This result is interesting given the findings that girls and women have strong interactive skills that facilitate collaboration in close relationships (e.g., Maccoby, 2000). One possible explanation is that individual females outperformed individual males due to the interpersonal nature of the task or the social nature of females; however the collaborative process could also be affected by certain gender roles of older men and women. Despite the individual differences in performance, something interesting is occurring at the dyadic level because males were more influential in the everyday problem-solving outcome but women performed better than men. This interesting finding supports the current examination of everyday problem solving as a social rather than individual endeavor.

Although these gender similarities and differences were restricted to an older adult sample, similar results may occur among different adult age groups as well. The current study focused on how gender impacts objective collaborative everyday problem-solving outcomes in younger, middle-aged, and older adult married couples. Due to the findings stated above, gender differences between husbands and wives were examined using a less-structured task. 


\section{Problem-Solving Occasion}

Problem-solving occasion refers to whether a participant is completing a task individually or collaboratively and also whether individual performance comes before or after collaborative performance. Examining problem-solving occasion is theoretically important in order to determine gain, stability, and decline when initially working alone, then working collaboratively, and then to working alone again. For example, if individuals perform better when actively engaging in problem-solving tasks with a partner, then it can be inferred that collaboration was beneficial. Additionally, if individuals perform better when working alone after collaboration, then it can be inferred that knowledge was gained from collaboration and was transferred to independent problem-solving situations.

Margrett \& Marsiske (2005) assessed older adults working both individually (work alone condition) and with a partner (collaborative condition) on three different tasks. These two conditions were counterbalanced, so that half of the sample initially worked collaboratively followed by individually, and the other half of the sample initially worked alone followed by collaborating with a partner. Counterbalancing was done for all three tasks. Tasks described as structured in nature (i.e., having one correct solution) resulted in the second problem-solving performance being superior to the first performance; thus when the second performance was the work alone occasion, individuals might have retained the gains of collaboration from the first collaborative performance or perhaps participants experienced a practice effect. A somewhat opposite finding occurred for the tasks that were less structured in nature (i.e., solving social dilemmas, having more than one correct answer). Specifically, the second performance was lower than the first performance, perhaps due to fatigue or the nature of the scoring. Overall, 
these findings suggest possible differential effects of collaborative gain and transfer depending on the type of task.

Due to the paucity of literature with regard to problem-solving occasion and also due to the findings by Margrett and Marsiske (2005) regarding task and order effects, the current study implemented a design unique to the adulthood collaborative literature. In the current study, participants completed a task three times (three phases). All participants completed the task individually at Phase 1 (pretest) and Phase 3 (posttest). For two-thirds of the participants, Phase 2 was collaborative and for one-third of the sample, Phase 2 was individual. This design assessed individual gain, stability, and decline across time. These calculations were done by calculating performance change scores from Phase 1 to Phase 2, from Phase 2 to Phase 3, and from Phase 1 to Phase 3 (see Figure 1). Change or stability in performance has important implications for collaborative cognition training in that it is worthwhile to know whether individuals transfer what they experience during collaboration to independent situations when they have to complete a task individually.

\section{Critique of Current Literature}

Several contextual factors appear to be influential to collaborative outcome (i.e., age, partner familiarity, problem-solving occasion, and gender), and many unanswered issues remain in the existing literature pertaining to the impact of these factors on collaborative everyday cognition. Such unanswered issues include the following: (1) Inclusion of middle-aged adults in collaborative everyday cognition studies, (2) An increase in the number of studies employing age comparisons with regard to individual (i.e., cognition, perceptions of marital satisfaction, gender) and design factors (i.e., problem-solving occasion, task) in collaborative and everyday problemsolving studies, (3) A more comprehensive understanding of "couples' expertise”, marital 
duration, and marital satisfaction and how they impact collaborative problem-solving outcomes, (4) A deeper understanding of gender differences in objective collaborative outcomes.

\section{Statement of the Problem}

There is increased attention in the literature with regard to collaborative and everyday cognition, especially in later adulthood. One reason for this growing interest is the fact that some researchers argue that basic abilities, measured by traditional measures in a laboratory setting, focus heavily on individual performance and neglect to emphasize the importance of the contexts inherent in real-life everyday problem solving. Some researchers also theorize that social partners might help to improve cognitive performance (Rogoff, 1998; Staudinger \& Baltes, 1996), or possibly remediate individual cognitive decrements that occur later in life (Dixon \& Gould, 1996, 1998; Margrett \& Marsiske, 2005; Strough \& Margrett, 2002).

Although the published literature on collaborative cognition focused mainly on childhood (e.g., Rogoff, 1998), there is an emerging interest in collaborative outcomes in adulthood populations (for discussion see Strough \& Margrett, 2002). Additionally, middle-aged adults, to our knowledge, were not examined in the current collaboration literature and were only minimally examined in the everyday problem-solving literature (e.g., Heidrich \& Denney, 1994). It is important to understand middle-aged adults' performance because it is at this point in adulthood when individuals sufficiently accrued knowledge in social domains and also when cognitive abilities are still retained. It is also important to make additional age comparisons on everyday problem solving because traditional comparisons of different age groups on fairly contrived tasks may result in inappropriate interpretations about age differences. Examining collaboration on tasks that are relatively common to individuals on a day-to-day basis should provide more accurate evaluations of both performance and collaboration. Furthermore, studies 
in the adulthood literature did not yet investigate problem solving across time to assess for gains, stability, and declines in performance, especially in terms of how collaboration may improve one's own individual performance.

The current study attempted to replicate and extend the extant literature on cognitive collaboration in adulthood by utilizing a similar design as Margrett (1999; WED) and Margrett \& Marsiske $(2002,2005)$. This replication and extension was done in the following ways: First, performance outcomes (i.e., fluency and efficiency) on a commonly used everyday cognitive task were examined. Second, performance was assessed when working with a spouse compared to working alone, and selected aspects of marital quality, which would predict optimal collaborative performance, were also explored. Third, performance on an everyday problemsolving task was investigated across occasion. Examination of three performance phases permitted the examination of change in performance from individual performance to collaborative performance (i.e., Phase 1 to Phase 2) as well as the transfer of collaboration to subsequent individual performance (i.e., Phase 1 to Phase 3 and Phase 2 to Phase 3). Fourth, gender differences in collaborative performance and transfer were explored. $\underline{\text { Fifth}}$, an age group comparison between younger, middle-aged, and older adults was made regarding collaboration. Again, it is important to emphasize that the recent published literature on cognitive collaboration lacks the investigation of middle-aged adult collaborative performance.

\section{Research Questions and Expected Results}

Two primary research questions were addressed in the current study. The first question addressed group differences in everyday problem-solving outcome in terms of the number of safe and effective solutions generated (fluency) as well as a proportion score examining both the quality and quantity of responses (efficiency). The second question addressed individual reliable 
change in everyday problem-solving outcome and whether several factors predicted a change in performance.

RQ1: Were there group differences in collaborative everyday problem-solving outcome?

Hypothesis 1. According to Margrett \& Marsiske (2002), there was a slight advantage for women on a less-structured task for total safe and effective solutions. Therefore, a significant main effect of gender was expected. Specifically, it was expected that females would outperform males on the everyday problem-solving task on both fluency and efficiency.

Hypothesis 2. A significant interaction between problem-solving condition and problemsolving phase was hypothesized. Specifically, it was anticipated that Phase 1 pretest performance would be the same for both conditions, yet Phase 2 performance would be higher in the experimental condition than the control condition due to the fact that collaboration was found to boost everyday problem-solving performance (Dixon \& Gould, 1996; Margrett, 1999; Staudinger $\&$ Baltes, 1996). The mean differences in performance outcome between Phase 2 and Phase 3 posttest in the experimental group (e.g., transfer from collaboration) compared to the control group was exploratory in the current study. It was presumed that the magnitude of the Phase 3 scores in the experimental condition would fall between Phase 1 and Phase 2 scores. Lastly, the control group was expected to show slight retest effects.

Hypothesis 3. The hypothesized main effect and interaction were expected to be qualified by a significant three-way interaction between age, condition, and problem-solving phase. Specifically, it was expected that older adults would gain more during collaboration compared to younger and middle-aged adults, thus minimizing or eliminating age differences at Phase 2 and 3 (Staudinger \& Baltes, 1996). Although it was anticipated that older adults would gain more from collaboration, it was expected that middle-aged adults would obtain the highest overall mean on 
the EPSI across all three problem-solving phases, despite the condition to which they were assigned (Denney \& Pearce, 1989; Heidrich \& Denney, 1994).

RQ2: What was the frequency of individual change, and was individual change predicted?

Hypothesis 4: The frequency of individual change in problem-solving outcome was exploratory; however, it was expected that more individuals in the experimental condition would improve from Phase 1 to Phase 2 and Phase 1 to Phase 3 compared to the control condition. This hypothesis was based on the idea that collaboration should be beneficial to individual performance. It was also expected that older adults would experience a greater amount of individual improvement in these two change scores compared to younger and middle-aged adults (Staudinger \& Baltes, 1996). Due to prior research as well as the focus on community-dwelling, familiar, married spouses in the current study, it was also anticipated that there would be very few participants classified as "declined." The prior study upon which the current study is based, found no familiar dyads (i.e., spouses) in which an individuals demonstrated reliable decline when comparing individual and collaborative performance (Moss, 2003).

Hypothesis 5: It was expected that aspects of marriage would predict individual reliable change. Specifically, individuals who were more satisfied with their marriages would experience more positive reliable change from collaboration than those who did view their marriage as highly (Margrett, 1999). Therefore, it was expected that marital satisfaction would be a significant predictor of status classification (i.e., those who improve, remain stable, decline). Similarly, levels of conflict in marriage could affect the collaborative process and subsequently affect classification status. Finally, those who were married longer may be more likely to develop “couples' expertise” (Carstensen, Levenson, \& Gottman 1995); it was expected that 
participants in longer marriages would experience more improved reliable change compared to those in shorter marriages.

Hypothesis 6: Due to the fact that basic cognitive ability relates to everyday problem solving (Allaire \& Marsiske, 1999; Denney \& Pearce, 1989), it was expected that measures of basic cognition (i.e., inductive reasoning, and verbal ability) would predict classification status. Specifically, it was expected that those who decline will score lower on basic cognitive abilities.

Hypothesis 7: Based on the findings between younger and older adults on everyday problem solving (Denney \& Pearce, 1989; Denney, Pearce. \& Palmer, 1982; Marsiske \& Willis, 1995) as well as collaborative outcome (Dixon \& Gould, 1998), it was anticipated that age would be a significant predictor of classification status with those who show the most reliable improvement also being older in age.

\section{Method}

\section{Participants}

A total of 45 legally married and cohabitating couples (younger $N=15$; middle-aged $N=$ 15 , older $N=15$ ) from West Virginia and Pennsylvania participated in the current study. Couples were recruited via media advertisements, community centers, religious affiliations, marriage licenses, and snowballing techniques in an attempt to increase sample heterogeneity. Sessions were conducted in a laboratory setting $(N=32$ couples $)$ or at participants' homes $(N=$ 13 couples). Each participant had a choice between receiving extra credit for a psychology course or a small honorarium $(\$ 7.50)$ for their participation. People who successfully referred participants to the study received $\$ 5.00$ per referral ( $N=3$ individuals). 


\section{Inclusion Criteria}

The following criteria were established for participant inclusion (based on Margrett, 1999) and all were met in the current study: (1) Participants were 18 years of age or older. Specifically, targeted age groups were younger (20-30 years), middle-aged (45-55 years), and older adults (70-80 years). (2) Couples' ages were within 5 years of each other and both spouses were in the same age group (i.e., younger, middle-aged, older); (3) Participants were legally married and currently residing with a spouse of the opposite sex; (4) Participants had a qualified spouse who was willing to participate; and (5) Participants reported an absence of impairment on the three Activities of Daily Living (i.e., ADL; bathing, dressing, and personal hygiene).

The rationale behind the inclusion criteria was as follows: (1) The study examined an adult life-span sample with a focus on age differences between younger, middle-aged, and older adults. Therefore, the aforementioned age ranges were initially targeted in hopes of obtaining similar mean ages as Denney and colleagues in their developmental studies of practical problem solving. The age ranges for the current study were younger (20-34 years), middle (35-57 years), and older (64-87 years) adults. With the exception of one participant aged 35 years in the middle-aged group, the obtained ages were similar to the majority of studies that examined age differences in everyday problem solving (Thornton \& Dumke, 2005). (2) The decision to only include spouses that were no more than 5 years apart in age was to prevent any possible confounds of age discrepant couples affecting the results. Nettles and Loevinger (1983), for example, found that married couples who were more discrepant in age experienced increased problems in their marriage compared to those who were closer in age. Another reason for this requirement was due to the fact that participants had to fall within the same age range based on the nature of the study examining age differences. (3) Different types of couples (married, 
cohabitating, dating) or dyads (e.g., parent-child) may differ in individual and relationship backgrounds. For instance, Glick and Spanier (1980) illustrated differences in education, employment status, occupational group, and income between married and unmarried couples in the United States. Additionally, Kotkin (1983) found that cohabitating couples were more egalitarian than those who chose to marry. These characteristics could act as confounds to the outcome of the study; thus only married, cohabitating couples were targeted. (4) Due to the fact that participants had to collaborate with a spouse, the design of the experiment required both spouses to be present during the study. (5) Presence of ADL limitations increases the potential risk of biasing the collaborative patterns due to a caregiver-care recipient role (Margrett, 1999).

\section{Total Sample}

Forty-five married couples (45 males, 45 females) comprised the total sample of tested participants. Participants ranged in age from 20 to 87 years. Age was precisely calculated at the time of participation based on the year, month, and day of birth. The mean age of younger, middle-aged, and older adults was $25.73(S D=3.33), 45.95(S D=4.78)$, and $75.29(S D=6.83)$ years, respectively. The majority of the participants were White $(94.4 \%)$, highly educated $(M=$ 15.35 years, $S D=2.36$ ), and earned a median yearly income of $\$ 40,000$. Younger, middle-aged, and older couples were married an average of $2.40(S D=2.24), 16.03(S D=9.08)$, and 47.85 $(S D=16.21)$ years, respectively. As expected, participants in the three age groups differed significantly in age, marital length, education, and income (See Table 1).

Non-participating subsample. Independent sample t-tests were conducted for individuals who completed the study $(N=90)$ compared to individuals who never entered into the study (e.g., did not express interest after a phone screener) or did not show up to participate $(N=39)$. The non-participating individuals did not have a participation date; therefore, age and marital 
length were calculated by subtracting the birth or marital year reported on the phone screener from 2005 because that is all the information that was obtained for the non-participating subsample. There were no significant differences in basic demographic characteristics between those who participated in the study and those who did not (See Table 2).

Experimental versus control subsample. Participants were assigned to one of two experimental conditions. One third of the participants were randomly assigned to work alone three times (control condition) whereas two thirds of the participants were randomly assigned to initially work alone, collaborate with their spouse, and then work alone again for the three problem-solving phases (experimental condition). Table 3 compares the characteristics of the control and experimental conditions. These two groups did not differ in terms of age, education, income, length of marriage, ethnicity, or cognitive performance.

\section{Design}

The design of this experiment included two within-subjects factors (i.e., Gender, Problem-solving Phase) and two between-subjects factors (i.e., Problem-solving Condition, Age Group). The first within-subjects factor, Gender, referred to the partnership of husband and wife. This partnership is referred to as gender in the document because the results are divided by males and females. Gender was treated as a within-subjects variable to control for the dependency of the data between husband and wife (Campbell \& Kashy, 2002). The second within-subjects factor, Problem-solving Phase, referred to the intervals or occasions of problem solving and to the fact that each participant completed a problem-solving task three times. The first betweensubjects factor, Problem-solving Condition, referred to whether the participants completed the problem-solving task individually before and after collaboration (Experimental group: baseline collaboration - posttest; see Figure 1) or whether participants completed the problem-solving 
task individually three times (Control group: baseline-individual-posttest; see Figure 1). Assignment to experimental and control groups were conducted randomly within in each age group prior to participation. The second between-subjects factor, Age Group, consisted of three levels and represented the three age groups examined in the study (younger, middle-aged, and older adults).

\section{Procedure}

After a brief telephone screening to ensure that participants met the inclusion criteria, a pre-session packet was sent to each couple and collected at the time of participation. One married couple and one administrator (two administrators were present during training) met at a mutually agreed upon location (i.e., lab or home). Participants were then administered several pencil and paper questionnaires to complete individually in a common space. After the paper and pencil segment was completed, participants were asked to take a short break before beginning the problem-solving portion of the study.

Couples were randomly assigned to a problem-solving condition (i.e., experimental, control), and each problem-solving condition consisted of three problem-solving phases. For every phase, a parallel form of the task was completed. Figure 2 depicts the session procedure and the number of participants in each condition. The entire session lasted approximately 1.5-2.5 hours.

Experimental Problem-Solving Condition (Baseline-Collaboration-Posttest)

Overview. Each participant completed the problem-solving task independently (baseline phase), then with his or her spouse (collaborative phase), and then again independently (posttest phase). Administrators frequently checked participant behavior through a two-way mirror to detect unwanted collaboration during individual problem solving and to also check for 
collaboration during dyadic problem solving. In addition to the administrator checks, a video camera was used during individual problem solving to record participant behavior and check for the absence of communication. Videotaping was also used during the collaborative phase as a manipulation check for occurrence of collaboration and also for future analyses (e.g., interactive styles). Participants were explicitly made aware of the reasons why videotaping was used (i.e., to deter speaking during the work alone phases and to check for collaboration during dyadic phases). These methods were employed to ensure treatment fidelity and participant adherence to protocol.

The order of the forms that the participants received across the three phases was counterbalanced across dyads, which resulted in six possible combinations. A total of three forms were used. Form order was randomly assigned to the dyad without replacement. Additional discussion regarding form order may be noted in the Results section below.

Baseline Phase. During the baseline phase, participants individually completed the Everyday Problem-Solving Inventory (EPSI; Cornelius \& Caspi, 1987). Partners remained in the same room during every problem-solving phase to control for social facilitation effects (Margrett \& Marsiske, 2002; Hart, Bridgett, \& Karau, 2001). Note that the participants were instructed to not communicate or share answers throughout the baseline phase. It was stressed that this was an individual task. At the onset of the problem-solving phase, participants were instructed to write down his or her answers to the presented everyday problems. It was also emphasized to the participants to generate as many safe and effective solutions as possible before proceeding to the next item.

Collaborative Phase. During the collaborative phase of the experimental condition, two spouses worked together to solve hypothetical everyday tasks. Participants were encouraged to 
discuss each of the problems presented. Administrators emphasized that this task was a collaborative one; however, each individual wrote down his or her own responses. In other words, participants were not required to generate a single consensual solution for each problem but rather were given the opportunity to discuss possible solutions with their spouse. These instructions allowed participants to generate as many possible answers collaboratively and then individually choose the answers to write down on paper (see Margrett, 1999). In everyday life people are not necessarily required to generate a common solution to a problem and may choose to use the solution(s) of their personal choice (e.g., what was successful in the past). Due to the fact that individual differences exist between people, a solution that is successful for one person may not be successful for another. Most importantly; however, is the fact that analyses in the current study required scores for males and females. Therefore, it was essential to have husbands and wives complete separate forms. The study was not interested in dyadic problem-solving outcome but rather individual outcome as a result of collaborative discussion.

Posttest Phase. During the posttest phase of problem solving, participants were asked to complete the problem-solving task independently as in the baseline phase. Similar to the baseline phase, participants remained in the same room as their spouse but were instructed not to communicate about their individual solutions. Participants were once again reminded to generate as many safe and effective solutions to each problem and to not discuss their answers with their partner.

\section{Control Problem-Solving Condition (Baseline-Individual-Posttest)}

The procedure for the control condition was analogous to the experimental condition. The only difference between these two conditions was that participants in the control condition completed the problem-solving task three times individually (individual baseline, individual 
Phase 2, individual posttest) to examine test-retest (e.g., practice, fatigue) effects. Similar to the experimental condition, all three phases were videotaped to record any participant behavior.

\section{Measures}

This study examined individual and collaborative outcomes in everyday problem solving as well as potential predictors of problem-solving performance. A summary of the measures included in the study is provided in Appendix A. Several measures were administered to assess participants' basic cognitive abilities, personality, and marital relationship. All of the measures described below are commonly used assessments and are representative of the constructs of interest.

\section{Telephone Screening and Demographics}

To assess for the participant inclusion criteria for the study, potential participants answered relevant information as part of a screening process. Questions regarding age, marital status, living arrangement, and Activities of Daily Living (ADL; e.g., bathing, dressing, personal hygiene) were used to screen individuals for eligibility to participate in the study. Individuals who did not fit the inclusion criteria $(N=23)$ were not considered for further participation and were asked for their permission to keep their information on file for future studies.

Additional questions regarding detailed demographics were obtained from the completed pre-session packet. Specific areas included functional status (Pfeffer, Kurosaki, Harrah, Chance, \& Filos, 1982), Instrumental Activities of Daily Living (IADLs; Lawton \& Brody, 1969), and other self-reported assessments such as income, education, ethnicity, gender, and health.

\section{Inductive Reasoning}

The Letters Series Test (Thurston, 1962) was used to assess inductive reasoning, which is the ability to infer relationships from specific information provided. Participants were presented 
with a series of letters that represented a pattern. Participants had to choose which letter would come next in the series out of the five answer choices provided. Participants had 6 minutes to complete as many items as possible. The measure was scored based on the total number of correct responses.

Perceptual Speed

A 48-item Number Comparison test (Ekstrom, French, Harman, \& Darman, 1976) was used to assess perceptual speed. During this 1.5 minute timed-test, participants compared two numbers in order to determine if the numbers were the same or different. Participants were told to place an " $\mathrm{X}$ " on the line between the two numbers if they were not the same and to leave the space blank if the numbers were the same. Perceptual speed performance was assessed by summing the total number of items that were correct and subtracting the number of items that were incorrect. This scoring procedure allowed for the assessment of accuracy and speed.

\section{Verbal Ability}

Verbal ability was assessed using both the Vocabulary and the Advanced Vocabulary subtests (Ekstrom, et al., 1976). The use of these two assessments was similar to Gould and Dixon (1993) and was the rationale behind including the four assessments of verbal ability in the current study. Participants first completed a 36-item Advanced Vocabulary test followed by a 36item Vocabulary test. Each 36-item test was subdivided into18-item segments, which lasted 4 minutes each (total time of 8 minutes for each vocabulary test or 16 minutes for both assessments combined). For all of the segments, participants were instructed to identify the correct definition of a word from a list of five choices. Participants received a score for the Advanced Vocabulary test as well as the Vocabulary test. Scoring was based on summing the total number of correct items for the Advanced Vocabulary and Vocabulary tests. 


\section{Marital Relationship}

The Couples Questionnaire was used to examine marital quality and satisfaction. This questionnaire contained 25 items with a 9-point Likert Scale to assess love, conflict/negativity, ambivalence, and maintenance behaviors experienced within the last year of marriage (Braiker \& Kelley, 1979). The current study also included a 10-item satisfaction subscale developed by Spanier (1976). Each construct in the current study was calculated based on the mean of the endorsed items within each subscale. A total marital quality score was calculated based on the average of all items on the Couples Questionnaire. An increased score on a subscale indicates stronger qualities of that marital quality subscale. The Couples Questionnaire was found to be a reliable measurement of young, middle-aged, and older adult couples across all subscales (for information related to use with younger samples see McHale, Freitag, Crouter, \& Bartko, 1991; for information related to use with older couples see Kimbler \& Margrett, 2005b). In the current study, alphas ranged from .65 for the maintenance subscale to .79 for love subscale with a total overall alpha for the Couples Questionnaire equal to .84. The alpha for the Dyadic Adjustment Scale in the current study was equal to .85 .

Everyday Problem-Solving Inventory: Primary outcome variable

Description. The Everyday Problem Solving Inventory (EPSI; Cornelius \& Caspi, 1987) was used to assess participants' everyday problem-solving abilities. The EPSI evaluates how individuals solve hypothetical social dilemmas. These vignettes represent social situations that adults are likely to encounter in six domains: consumerism, complex information, home management, family, friend, and work (see Appendix B) The dilemmas across the domains vary in terms of who is responsible for the problem in the sample vignette (e.g., Self: You [italics added] lost or broke an expensive item you borrowed from someone; Other: A family member 
[italics added] behaves in a manner you dislike very much.). In the original assessment, Cornelius and Caspi (1987) presented four answer choices to the respondents for each item in the measure.

The format of the EPSI in the current study is slightly different from the original assessment. No answer choices were provided because using an open-ended format was believed to facilitate dyadic interaction in the collaborative condition. This format was also used in previous studies (Denney \& Pearce, 1989; Margrett \& Marsiske, 2002, 2005; Marsiske \& Willis, 1995). Participants were asked to generate as many safe and effective answers as possible to resolve each social dilemma. Participants were told to proceed to the next social problem only after generating as many safe and effective responses as possible.

As the close-ended version was not used, the current study administered three parallel forms that were based on the original close-ended version of the EPSI. In Margrett \& Marsiske (2002), two open-ended parallel forms were used, which possessed high internal consistency (Form $1 \alpha=.85$; Form $2 \alpha=.86$ ). Those two forms were also used in the current study, and a third form (psychometrics mentioned below) was created after screening items for domain, social content, and age-relevancy. One item from each domain was selected based on social content, and age relevancy was considered based on the specific content of the items (e.g., "Medicare form" was changed to "complicated form" so that the topic would be equivalent across age groups). Each form contained a total of six items (i.e., one item from each domain).

Scoring/Coding. Scoring on the EPSI was based not only on the total number of safe and effective solutions generated, but also on the accuracy of safe and effective solutions. Therefore, each participant received both a total safe and effective score (i.e., a sum) as well as an efficiency score (i.e., a proportion). The proportion score accounted for both the quantity and quality of 
responses. The denominator of the proportion score was the total number of responses, and the numerator was the total number of safe and effective solutions generated.

Independent raters (e.g., research assistants) coded which responses from all participants were considered to be safe and effective or not safe and effective and then the proportion score was computed from these two numbers. The instructions for what constitutes safe and effective answers were based on the general scoring rules for the EPSI from Margrett and Marsiske (2002) and the guidelines created by Marsiske \& Willis (1995) Appendix C contains the general scoring rules for the EPSI. During coding, the raters used the decision rule "Does the participant's solution make sense, and are they actually doing something? If so, would the action impose harm to themselves or others?" Effective solutions could be based on first steps that people could use to solve problems (e.g., "I would walk away from the situation to calm down.") or the likelihood that the social dilemma would be resolved (e.g., "I would ask my boss about how I could improve my work.”). Ineffective solutions were based on potential harm imposed (e.g., "I would 'tell off" my boss" or "I would shoot the dog that is barking."), words of wisdom (e.g., "One should choose their friends wisely."), emotional expressions (e.g., "I would be upset."), or solutions that were unclear and did not make sense in relation to the problem stated. Appendix B depicts each vignette with both effective and ineffective sample solutions.

Coders practiced on previously coded forms from a different study (Form 1 and Form 2; Margrett, 1999). Once coders reached $90 \%$ agreement, they were able to begin coding the EPSI forms in the current study. Weekly meetings were held to assess inter-rater reliability on a random $20 \%$ of the protocols. Drift was also assessed from week to week, and any problems with adherence to the guidelines were discussed and resolved. A mutual agreement was reached after a discussion about discrepant coding, and notes were also made in a codebook to prevent a 
similar problem in the future. These precautions were taken to ensure the fidelity of the study and the coding procedures. In the current study, percent agreement was $90.9 \%, 89.4 \%$, and $87.8 \%$ for Forms 1, 2, and 3, respectively throughout the course of coding (See Table 4 for reliability details).

Differences between coders in the total number of safe and effective solutions were examined by conducting independent sample t-tests. For Form 1, there were no significant differences between the two coders on the total number of safe and effective solutions, $t(88)=$ $1.41, p>.05$. For Form 2, there was a significant difference in the total number of safe and effective solutions coded, $t(88)=2.21, p<.05$. Coder 1 possessed a higher mean than Coder 2 . For Form 3, there were no significant differences between the coders in the total number of safe and effective solutions, $t(88)=1.07, p>.05$.

To investigate the potential problem for Form 2, coder differences in the total overall number of solutions (i.e., including effective and ineffective solutions) that were generated by participants on Form 2 were examined. The rationale for this analysis was due to the fact that if coders differed in the overall total number of solutions generated, then it is likely that the difference in safe and effective solutions on Form 2 was due to coincidence (i.e., Coder 1 received Form 2's in which participants generated more overall solutions, subsequently resulting in more safe and effective solutions). There was in fact a significant difference between Coder 1 and Coder 2 on overall number of solutions, $\mathrm{t}(88)=2.22, \mathrm{p}<.05$, suggesting that Coder 1 was not biased in coding more safe and effective solutions but that the participants were actually generating more solutions overall (effective and ineffective solutions). To further clarify the significant difference in safe and effective solutions on Form 2, coders were randomly assigned protocols to code a priori within each form. Therefore, it is very unlikely that coders would code 
three protocols for the same participant. This random assignment of forms along with counterbalancing across phases (Form 2 was completed at different phases) suggests that the potential (but unlikely) error would be randomly dispersed across participants and phases. Therefore, it is not likely that the coder difference for Form 2 would systematically affect the findings of the study and was not viewed as a problem or limitation of the study.

Psychometrics. The EPSI was chosen for the current study because it has previously been used in the developmental and collaboration literature (e.g., Blanchard-Fields, Stein, \& Watson, 2004; Margrett \& Marsiske, 2002), and has possessed good psychometrics. In Cornelius and Caspi (1987), for example, split-half reliabilities ranged from .53 (consumerism) to .77

(information) and the total measure was .92. The reliability of the EPSI in the current study was calculated based on the total number of safe and effective solutions. The alpha coefficients were $.87, .87$, and .83 for Form 1, 2, and 3, respectively. Total safe and effective reliability coefficients for each domain summed across the three forms ranged from .56 (friend) to .78 (family). Therefore, total scores were rather consistent with forms and across domains. This reliability should be emphasized, as future researchers interested in parallel forms of the EPSI could administer the items used in the current study.

\section{Data Management}

\section{Missing Data}

The nature of all missing data was examined. It appeared that all data were likely to be missing at random because the missing items occurred on different forms, they were different item numbers, and differed across different participants (i.e., not all one age group). One hypothesis is that pages stuck together, so participants unintentionally skipped an item. For Form 1, missing data affected 4 out of 90 participants (4.44\%). For Form 2, 2 out of 90 participants 
$(2.22 \%)$ were affected, and 6 out of 90 participants $(6.67 \%)$ were affected with missing data for

Form 3 . Note that the percentage of missing data is actually very small because these participants were only missing one item out of a total 18 items.

Prior to conducting analyses, individual missing item data on the EPSI forms were replaced using the mean of the participant's own performance on the form with the missing item (Schafer \& Graham, 2002). To support this method of replacing missing data, a correlation analysis was conducted. It was believed that if performance on each item was related to each other at Phase 1, Phase 2, and Phase 3, domain of item would not affect performance. Every item completed at each phase was correlated significantly with each other (Phase 1: $r=.22-.67$, Phase 2: $r=.24-.61$, Phase 3: $r=.23-64)$. These significant correlations justified replacing the missing data with the individual's mean on the form rather than with the means within each domain. Normality of Data

Skewness and kurtosis were examined using SPSS version 9.0 to assess the normality of the data. Values for skewness did not reach 1 and values for kurtosis did not reach 3. Therefore, any slight deviations from normality would not make a substantial difference in the analyses (Tabachnick \& Fidell, 2001).

Results

\section{Overview of Analyses}

The results are divided into two sections corresponding to the primary research questions, and further subdivided based on hypotheses addressed in the Introduction. The first set of analyses examined group-level differences in problem-solving performance. These analyses were conducted using the total number of safe and effective solutions generated as well as using a calculated efficiency proportion score (i.e., total number of safe and effective solutions divided 
by the total overall number of solutions generated).The second set of analyses focused on individual-level change in performance. Alpha was set equal to .05 for all analyses. Analyses addressed the conceptual question of how design variables (i.e., problem-solving condition, problem-solving phase) and individual factors (age, gender, marital quality, and cognition) affect everyday problem solving when working either individually and/or collaboratively with a spouse.

Are there group differences in collaborative everyday problem-solving outcome?

This section is divided by the two problem-solving outcome variables in the study, beginning with total number of safe and effective solutions (i.e., fluency score) followed by the computed proportion score (i.e., efficiency score). For each analysis of variance (ANOVA), appropriate simple interaction effects and/or simple comparisons were performed when higherorder interaction terms were significant. This is in line with Keppel (1991), who suggests that in order to produce precise interpretation of the results, these steps should be followed.

In order to control for the dependence of observations in spousal scores, analyses for group differences were conducted at the dyadic level ( $N=45$ dyads). Consequently, male and female partner scores served as the dependent variable, and gender was treated as a withinsubjects factor. The inclusion of male and female scores followed the recommendations of previous marital research which included a spousal factor due to the nature of dependence of observations (e.g., Smith, Gallo, Goble, Ngu, \& Stark, 1998). By permitting the extraction of the "couples' related variance" in a repeated-measures error term, the power of the design to detect hypothesized effects was substantially boosted. Thus, the unit of analysis in the current study was the dyad; individuals (i.e., the husband and wife in each dyad) were examined as a withindyad factor in the group-level analyses. 


\section{Analysis 1: Fluency Score on the EPSI}

The fluency score of the participants was calculated by summing the total number of safe and effective solutions across the six items of each form. Specifically, each participant received three separate scores (Phase 1, Phase 2, Phase 3). The average fluency scores for the total sample were $20.28(S D=8.38), 19.16(S D=8.27)$, and $19.16(S D=7.48)$ for Phase 1,2 , and 3, respectively (See Table 5 for means and standard deviations by age group).

As previously mentioned, a main effect for gender, an interaction between problemsolving phase and problem-solving condition, as well as a three-way interaction between age group, condition, and phase were hypothesized. Therefore, a 3 (age group) x 2 (gender) x 2 (problem-solving condition) x 3 (problem-solving phase) repeated measures ANOVA was conducted to assess the first three hypotheses in the current study. Gender and problem-solving phase refer to the two repeated within-subjects factors. Age group and problem-solving condition refer to the two between-subjects factors. The dependent variable was the fluency score obtained on the EPSI. The analysis revealed a significant four-way interaction, $F(4,78)=2.83, p<.05, \eta$ $=.11$ (see Figure 3 ). There were no main effects, first-, second-, or third-order interactions (see Table 6).

Follow-up ANOVAs were conducted to permit further interpretation of the complex interaction. In the instance of a three-way or higher-order interaction, one should conduct simple interaction effects that are conceptually most interesting or pertinent to the research question (Keppel, 1991). Therefore, to follow-up the significant four-way interaction, repeated measures ANOVAs were conducted separately for males and females. Decomposing the analysis at the level of gender was chosen because gender was exploratory in this study, whereas age group differences were of most interest. Theoretically, it made sense to run separate analyses for males 
and females, allowing for the statistical comparison of younger, middle-aged, and older adults at each level of gender.

Males. A 3 (age group) x 2 (problem-solving condition) x 3 (problem-solving phase) repeated measures ANOVA was conducted for males' fluency scores on the EPSI. Analyses revealed a significant three-way interaction, $F(4,78)=5.29, p<.001, \eta=.22$ (see Figure 3 ). There were no main effects or lower order interactions (see Table 7). To follow-up the significant interaction between age group, problem-solving condition, and problem-solving phase, simple interaction effects were calculated separately for experimental and control groups within the male sample. Again, this method was chosen to allow for age comparisons.

For males in the control condition, a 3 (age group) x 3 (problem-solving phase) repeated measures ANOVA revealed no significant two-way interaction, $F(4,24)=2.04, p=.12, \eta=.25$ and no main effects for problem-solving phase, $F(2,24)=.14, p=.87, \eta=.03$, or age group, $F$ $(1,12)=.22, p=.81, \eta=.04$. Due to the primary interest in age differences, simple effects were calculated between age groups at each phase. These analyses revealed that there were no significant simple effects between any of the age groups (see Table 8 for estimated marginal means).

For males in the experimental condition, a 3 (age group) x 3 (problem-solving phase) repeated measures ANOVA revealed a significant interaction, $F(4,54)=4.95, p=.01, \eta=.27$. There were no significant main effects for problem-solving phase, $F(2,54)=.43, p=.66, \eta=$ .03 , or age group, $F(1,27)=1.47, p=.25, \eta=.10$. To follow-up the simple interaction, simple simple effects were examined between age groups at each phase. There were no significant simple simple effects for age group at Phase 1 or Phase 3. During Phase 2 (i.e., collaboration); however, there was a significant difference between younger and older males $(p<.05)$ and 
between middle-aged and older males $(p<.05)$ with younger and middle-aged males outperforming older males (see Table 8 for estimated marginal means).

Females. A 3 (age group) x 2 (problem-solving condition) x 3 (problem-solving phase) repeated measures ANOVA was conducted for females' fluency scores on the EPSI. The ANOVA revealed no significant interactions or main effects (see Table 9). To explore potential differences and parallel the analyses for males, simple effects were examined within females to assess age differences across the three problem-solving phases at each problem-solving condition (See Figure 3)

For females in the control condition, none of the simple effects were significant. At Phase 3 there was a trend, indicating that middle-aged females performed better than older females ( $p=$ $.05)$. See Table 8 for estimated marginal means.

For females in the experimental condition, simple effects revealed both trends and significant effects. At Phase 1, younger females significantly outperformed older females ( $p<$ $.05)$. At Phase 2, there was a trend suggesting that younger females performed better than older females $(p=.08)$. At Phase 3 , younger females significantly outperformed older females ( $p<$ .05 ), and there was a trend suggesting that younger females performed better than middle-aged females $(p=.10)$.

\section{Analysis 2: Efficiency Proportion Score on the EPSI}

A second ANOVA examined group-level differences and was conducted with the efficiency score as the dependent variable. This analysis examined the first three hypotheses stated in the Introduction section. The efficiency score was computed by taking the total number of safe and effective solutions and dividing it by the overall total number of solutions provided (i.e., fluency score/total overall solutions). Average efficiency scores on the EPSI for the total 
sample were .94, .92, and .93 for Phase 1,2, and 3, respectively. As indicated by the mean of the efficiency scores, most individuals recorded a majority of safe and effective solutions and appeared to omit solutions that were not safe and effective, thus limiting the variability in scores. Means and standard deviations for the efficiency score by age group can be seen in Table 5. A 3 (age group) x 2 (gender) x 2 (problem-solving condition) x 3 (problem-solving phase) repeated measures ANOVA was conducted ${ }^{2}$ The dependent variable was the calculated efficiency score on the EPSI. There was a significant Gender x Age Group interaction, $F(2,78)$ $=4.82, p<.05, \eta=.20$ (see Figure 4). No other interactions were significant (see Table 10); however there was a trend for the Problem-solving Condition x Age Group interaction, $F(2,39)$ $=3.22, p=.05, \eta=.14$ (see Figure 5). Both of the interactions were further analyzed, but interpretations for the Age Group x Problem-Solving Condition must be made with caution.

To follow-up the significant Age Group x Gender interaction, simple effects were conducted examining mean differences in efficiency scores between younger, middle-aged, and older adult males and females. Simple effect analyses revealed a significant difference between younger males and older males $(p<.05)$, with older males outperforming younger males. There were no significant differences between younger and middle-aged males $(p>.05)$ or middleaged and older adult males $(p>.05)$. There were no significant differences between younger, middle-aged, and older adult females $(p>.05)$ on efficiency scores (refer to Table 11 for estimated marginal means).

To follow-up the Problem-solving Condition x Age Group trend, simple effects were conducted examining differences between younger, middle-aged, and older adults within each condition. For the control condition, there were no significant differences between younger, middle-aged, and older adults $(p>.05)$. In the experimental condition, older adults significantly 
outperformed younger adults $(p<.05)$. Furthermore, there was a trend between younger and middle-aged adults $(p=.06)$ with middle-aged adults outperforming younger adults (refer to Table 12 for estimated marginal means).

What is the frequency of individual change, and which factors are predictive of change?

To assess individual-level performance change, a standard error of measurement (SEM) was calculated for each participant. Reliable performance was assessed from Phase 1 to Phase 2, Phase 2 to Phase 3, and Phase 1 to Phase 3 (i.e., three change scores; refer to Figure 1) and was done so according to the information provided in Dudek (1979) and Schaie (1989). Reliable performance change for the first classification (Phase 1 to Phase 2) was defined by a Phase 2 score that was greater than or equal to one SEM above or below an individual's Phase 1 score. Reliable change for the second classification (Phase 2 to Phase 3) was defined by a Phase 3 score that was greater than or equal to one SEM above or below the individual's Phase 2 score. Lastly, reliable change for the third classification (Phase 1 to Phase 3) was defined by a Phase 3 score that was greater than or equal to one SEM above or below the individual's Phase 1 score. These analyses were conducted at the individual level ( $N=180$ individuals).

The classification of individuals into groups was based on the following. If the second point of measurement was greater than one SEM above the first point of measurement, the individual was classified as "improved". If the score fell below one SEM, the individual was classified as "declined". All other scores were classified as "stable". Analogous calculations were made for the experimental and control conditions.

Theoretically speaking, it is important to know if individuals declined, remained stable, or improved across the three phases of problem solving. Therefore, all three classification 
groupings (improved, stable, and declined) were examined at each point of measurement (Phase 1 to 2 , Phase 2 to 3 and Phase 1 to 3 ).

The way that the data are set up did not allow for the calculation of the SEM for the efficiency score. A participant who scored a 1.00 at any phase of problem solving would not have the opportunity to reliably improve because 1.00 is the maximum efficiency value that one could earn. Thus, it was not logical to assess individual-level change for efficiency scores. Therefore, reliable individual-level change was only assessed for the fluency score. Frequency of Individual Change

Control Condition. The frequency of participants who improved, remained stable, and declined was assessed for each change score measurement. It was expected that individuals in the control group would demonstrate stability across all three phases. From Phase 1 to Phase 2, $6.7 \%$ improved ( 1 younger and 1 older adult), 90\% remained stable, and $3.3 \%$ declined ( 1 older adult). From Phase 2 to Phase 3, 6.7\% improved (1 younger and 1 older), 73.3\% remained stable, and $20 \%$ declined (3 younger, 2 middle, 1 older). From Phase 1 to Phase 3, 3.3\% improved (1 older), 90\% remained stable, and $6.7 \%$ declined ( 1 middle, 1 older).

Experimental Condition. It was expected that most individuals would improve, and few participants would decline. From Phase 1 to Phase 2 (i.e., effects of collaboration), 13.3\% improved (2, younger, 5 middle, 1 older), $63.3 \%$ remained stable, and $23.3 \%$ declined (4 younger, 3 middle, 7 older). This pattern was significantly different when compared to the control condition, $\chi^{2}(1, N=90)=7.57, p<.05$. From Phase 2 to Phase $3,15 \%$ improved (5 younger, 1 middle, 3 older), 68.3\% remained stable, and 16.7\% declined (5 younger, 4 middle, 1 older). This pattern was not significantly different from the control condition, $\chi^{2}(1, N=90)=$ 1.33, $p>.05$ From Phase 1 to Phase 3, 10\% improved (2 younger, 2 middle, 2 older), 80\% 
remained stable, and 10\% declined ( 3 younger, 1 middle, 2 older). This pattern was not significantly different from the control condition, $\chi^{2}(1, N=90)=1.63, p>.05$ (a visual depiction of the frequencies may be seen in Figure 6)

\section{Predicting Classification Status}

The control condition did not show a substantive amount of improvement or decline, and predicting classification status of individuals who were affected by collaboration was most relevant to the study objectives. Therefore, only the participants in the experimental condition were used in the analysis. Discriminant function analysis was used to determine if participants identified as improved, stable, or declined differed in terms of age, education, advanced vocabulary, inductive reasoning, marital length, marital satisfaction, and marital conflict. This analysis was conducted three times (i.e., change score 1, change score 2, change score 3 ; see Figure 1) Due to the size of the sample, all potential factors in the study could not be entered into the model. The aforementioned factors were chosen based on what was of interest to the author as well as which factors may predict improvement, stability, or decline based on previous research.

Phase 1 to Phase 2. A discriminant function analysis was conducted to determine whether the seven factors could predict classification status from Phase 1 performance to Phase 2 performance. Three of the factors produced significant differences between the groups; the others did not. Multivariate analysis revealed that the first discriminant function analysis reliably differentiated among the classification statuses (i.e., improve, stable, decline), $\lambda=.57, \chi^{2}(14)=$ $30.09, p<.05, R^{2}$-canonical $=.32$, but that the second function did not provide further reliable differentiation, $\lambda=.83, \chi^{2}(6)=9.93, p=.13, R^{2}$-canonical $=.17$. 
Table 13 presents the structure weights for the first discriminant function, revealing that inductive reasoning, advanced vocabulary, and education contributed to the discrimination between groups. Inspection of the standardized canonical coefficients, also shown in Table 13. revealed that because of the collinearity between education and advanced vocabulary, only inductive reasoning had a strong unique contribution to the function. On the basis of the results, this function was labeled cognitive ability. The means of the discriminant function analysis suggested that the decliners $(M=1.07)$ had the highest mean on cognitive ability, those who improved $(M=.53)$ had moderate means, while those who remained stable $(M=-.48)$ had lower means on cognitive ability. It was difficult to determine if these means are consistent with the interpretation of the function because little is known about the predictors of collaborative gain, stability, or decline. When trying to predict classification status from Phase 1 to Phase 2, 63.3\% of the individuals in the sample were classified correctly. In order to take into account chance agreement, a kappa coefficient was calculated. A moderate value of .40 was obtained.

Phase 2 to Phase 3. A discriminant function analysis was conducted to determine whether the seven aforementioned factors could predict classification status from Phase 2 performance to Phase 3 performance. Two of the factors produced significant differences between the groups; the others did not. Multivariate analysis revealed that the first discriminant function analysis reliably differentiated among the classification statuses (i.e., improve, stable, decline), $\lambda=.63, \chi^{2}(14)=24.88, p<.05, R^{2}$-canonical $=.30$, but that the second function did not provide further reliable differentiation, $\lambda=.90, \chi^{2}(6)=5.71, p=.46, R^{2}$-canonical $=.10$.

Table 14 presents the structure weights for the first discriminant function, revealing that marital conflict and education contributed to the discrimination between groups. Inspection of the standardized canonical coefficients, also shown in Table 14 revealed that both conflict and 
education had a strong unique contribution to the function. This function was simply labeled conflict and education. The means on the discriminant function analysis suggested that the decliners $(M=1.40)$ had the highest mean on conflict and education, those who remained stable $(M=-.34)$ and those who improved $(\mathrm{M}=.04)$ had lower means. The means, especially with regard to marital conflict, seemed to be consistent with the interpretation. When trying to predict classification status from Phase 2 to Phase 3, 61.7\% of the individuals in the sample were classified correctly. In order to take into account chance agreement, a kappa coefficient was calculated. A moderate value of .34 was obtained.

Phase 1 to Phase 3. A discriminant function analysis was conducted to determine whether the seven factors could predict classification status from Phase 1 performance to Phase 3 performance. Three of the factors produced significant differences between the groups; the others did not. Multivariate analysis revealed that the first discriminant function analysis reliably differentiated among the classification statuses (i.e., improve, stable, decline), $\lambda=.64, \chi^{2}(14)=$ 24.06, $p<.05, R^{2}$-canonical $=.26$, but that the second function did not provide further reliable differentiation, $\lambda=.86, \chi^{2}(6)=7.93, p=.24, R^{2}$-canonical $=.14$.

Table 15 presents the structure weights for the first discriminant function, revealing that marital satisfaction, marital length, and age contributed to the discrimination between groups. Inspection of the standardized canonical coefficients, also shown in Table 15, revealed that marital length contributed the most unique variance to the function. On the basis of the results, this function was labeled experience. The means on the discriminant function analysis suggested that those who remained stable $(M=.27)$ had the highest mean on experience, and those improved $(M=-.93)$ and those who declined $(\mathrm{M}=-1.50)$ had lower means on experience. The means are somewhat consistent with the interpretation of the function. When trying to predict 
classification status from Phase 1 to Phase 3, 70.0\% of the individuals in the sample were classified correctly. In order to take into account chance agreement, a kappa coefficient was calculated. A moderate value of .29 was obtained.

\section{Discussion}

The sections below provide a review of the study's research aims and findings as well as a discussion of how the findings related to the current literature.

\section{Review of Research Questions and Hypotheses}

The current study attempted to replicate and extend prior collaborative cognition work (e.g., Margrett, 1999; Margrett \& Marsiske, 2002, 2005) by examining the everyday problemsolving skills of younger, middle-aged, and older adults. Everyday problem solving occurred in a naturalistic state; that is, in the presence of a social partner (i.e., one's spouse) and outcomes were assessed at both the individual and dyadic levels. The research goals of the present study were to 1) assess performance outcomes on an everyday cognitive task across an adult life-span sample, 2) compare performance when working with a spouse to working alone and explore characteristics of the individual and the dyad that could potentially predict optimal collaborative performance; 3) examine the carry-over effects of collaboration to subsequent individual performance, 4) explore gender differences in collaborative performance; 5) investigate age group differences in collaborative everyday problem solving between younger, middle-aged, and older adults, and 6) determine the predictive value of several factors in classifying individuals who improved, remained stable, or declined across the phases of problem solving.

To explore these research aims, younger, middle-aged, and older adults completed several self-report assessments and cognitive ability measures, as well as everyday problemsolving items. On the everyday problem-solving task, participants worked either individually or 
with a partner. The problem-solving task included hypothetical interpersonal dilemmas in which participants were asked to generate as many safe and effective solutions as possible. All participants were randomly assigned to work alone across three problem-solving phases (control condition) or to an experimental condition in which baseline individual performance was followed by collaboration and then an individual posttest. A total of 45 legally married and cohabitating couples participated in this study.

\section{Review of Study Findings}

The following section provides a summary of the major findings of this study. The subsections focus on analyses that examine group differences in fluency scores, group differences in efficiency proportion scores, individual differences in fluency scores, and the value of factors hypothesized to predict collaborative improvement, stability, or decline.

The results of this study highlight the multidimensionality as well as the complex interplay of several factors that affect the outcome of everyday collaborative problem solving.

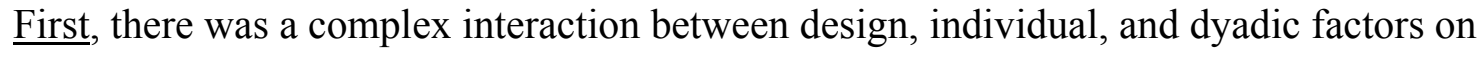
problem-solving outcome when assessing fluency. The patterns of everyday collaborative problem solving varied for males and females as well as for different age groups. In other words, collaboration was beneficial for some groups of participants but not others. Second, the same complex interaction was not found when assessing the efficiency proportion score. Findings varied based on the particular scoring method used in the study. Third, significant individual and design factors that predicted reliable change in performance varied based on which phases were compared (i.e., individual pretest to collaboration, collaboration to individual posttest, or individual pretest to individual posttest). Each of these findings is discussed in the subsections below. 


\section{Group Differences in Fluency}

The main question motivating this study was whether different factors (e.g., design elements, individual, and dyadic characteristics) affected everyday problem-solving outcome. As expected, the findings were complex. In the current study, gender, age, problem-solving condition, and problem-solving phase interacted to influence everyday problem-solving outcome. Due to this interaction, it was very difficult to determine exactly which factors were influential to the generation of safe and effective solutions for certain groups. The following descriptions summarize the results.

When comparing males in the control condition (i.e., completing the problem-solving task three times individually), younger, middle-aged, and older adults generated similar numbers of safe and effective solutions. The pattern of responses was different for males in the experimental condition. There were no age differences during pretest and posttest (Phases 1 and 3); however during collaboration, younger and middle-aged males generated more safe and effective solutions than older males.

The pattern of findings for females was slightly different compared to males. For females in the control condition, there were no significant age differences between younger, middle-aged, and older adults. In other words, across the three phases of individual performance, all age groups were similar in fluency. Females in the experimental condition exhibited a different pattern of results. During all three problem-solving phases (pretest, collaboration, posttest), younger females generated more solutions than older females. During the collaborative session, age differences were minimized, resulting in a trend in the findings.

It was anticipated that analyses would reveal a significant effect for gender; however the exploratory analysis demonstrated that the broader picture is more complicated than expected. 
Overall, analyses revealed that the patterns of everyday problem-solving outcome were quite different for males and females, depending on the condition, phase, and age of the participants.

\section{Group Differences in Efficiency}

Everyday cognition using the Everyday Problem Solving Inventory (EPSI) was also examined using an efficiency proportion score, which was calculated by dividing the total number of safe and effective solutions by the total number of overall solutions generated. Contrary to expectations, the results were different using this scoring method compared to the fluency method (i.e., generating as many safe and effective solutions as possible). Two interesting and informative results emerged: an Age Group x Gender interaction and an Age Group x Condition trend, which are summarized below.

The interpretation of the significant Age Group x Gender interaction revealed that when scores were collapsed across problem-solving condition and phase, older males outperformed younger males in efficiency scores. There were no differences; however, between younger, middle-aged, and older females. Overall, older males provided the most efficient responses.

The interpretation of the Age Group x Condition trend suggests that older adults in the experimental condition outperformed younger adults in the experimental condition. There were no age differences in the control group. Overall, older adults who were given the opportunity to collaborate produced more efficient responses on the EPSI than their younger counterparts. Individual Differences in Fluency

To further elucidate the group-level findings, examination of individual-level performance change was examined. Therefore, analyses were conducted to examine the number of people who improved, remained stable, and declined across the different phases in the control and experimental conditions. Based on previous research (Moss, 2003), it was expected that very 
few participants would decline across occasions due to practice for the control group and collaboration for the experimental group. As expected, results revealed that small percentages of individuals in the control and experimental groups declined in fluency scores. Surprisingly, however, collaboration did not have the expected impact on the experimental group. Although more individuals improved in the experimental group compared to the control group, very few participants reliably improved overall. This could be due to some individuals experiencing fatigue. Overall, the majority of the sample remained stable in fluency outcome.

\section{Predicting Group Status}

Predictors of reliable change in everyday problem-solving performance were examined for the experimental condition participants based on the study's focus on the effects of collaboration on everyday problem-solving performance. Results of the discriminant function analyses suggested a complex relation between several factors and individual reliable change in terms of fluency. The significant functions with the influential predictors are described below.

Comparing individual pretest performance to collaborative performance, inductive reasoning, advanced vocabulary, and education (i.e., labeled cognitive ability) significantly related to improvement, stability, or decline in everyday problem-solving performance. Individuals who had the highest mean on cognitive ability tended to decline from pretest to collaboration. Individuals who had moderate means on cognitive ability tended to improve, and individuals who had lower means on cognitive ability tended to remain stable from pretest to collaboration in terms of fluency on the EPSI.

Comparing collaborative performance to individual posttest, marital conflict and education significantly explained individual improvement, stability, and decline in everyday 
problem-solving performance. Individuals who possessed the highest means tended to decline, whereas individuals with lower means tended to either improve or remain stable.

Finally, comparing individual pretest performance to individual posttest performance, marital satisfaction, marital length, and age significantly predicted improvement, stability, or decline in fluency on the EPSI. Individuals with lower means tended to either improve or decline, whereas individuals with higher means remained stable in everyday problem-solving performance.

Implications

\section{Group Differences in Fluency}

Very little research has examined differential patterns between various groups in collaboration or everyday problem solving, particularly differences between males and females. Therefore the following section focuses on the explanations and implications for differential patterns in the control and experimental conditions, as the effects of collaboration (the experimental group) were primarily relevant to the research aims.

Control Condition. In previous research, younger and middle-aged adults typically performed better than older adults (e.g., Denney \& Pearce, 1989) with females performing better than their male counterparts on interpersonal everyday problem solving (Margrett \& Marsiske, 2002). It was expected that support for this hypothesis would be very likely for the control condition, considering that no collaboration was occurring across the three phases. Due to the fact that these participants were not collaborating, which could potentially boost performance and minimize age differences, age differences were expected to emerge. The results of this study (i.e., no age differences for males or females in the control group) did not support this hypothesis. 
Due to the fact that the extant literature emphasizes that middle-aged and younger adults outperform older adults (e.g., Denney \& Pearce, 1989; Heidrich \& Denney, 1994), the lack of significant age differences in the control condition was intriguing. One explanation for the prevalent age differences in problem-solving outcome is related to deficits in basic cognitive abilities that older adults face in later life (e.g., Allaire \& Marsiske, 1999). In the current study, there were age differences in inductive reasoning and perceptual speed performance but no age differences in verbal ability. When basic cognitive performance was examined in relation to everyday problem-solving ability in the current study, the correlations were moderate (ranging from .12 for Advanced Vocabulary to .29 for inductive reasoning). Perhaps this finding of no age differences in the control condition was due to the nature of the sample (e.g., highly educated, middle-class). Schaie (2000) found that higher education and enriching environments may deter the onset of cognitive decline. This could be true of the current sample, considering that most participants were well-functioning, highly educated, and of middle-class socioeconomic status.

Another theoretical explanation for the lack of age differences in male and female performance in the control condition is that older adults' experiences with everyday tasks across time may preserve everyday functioning in later age, despite possible cognitive declines in basic abilities (Baltes, 1993; Cornelius \& Caspi, 1987). Due to the fact that the trajectory of everyday problem-solving across the lifespan is currently unknown, as well as the fact that the current study did not assess participant experience with the presented vignettes, it was difficult to decipher a clear explanation for similar individual performances between younger, middle-aged, and older adults.

Experimental Condition. It was expected that age differences would be present in the experimental condition at pretest, but it was expected that these age differences would be 
minimized or nonexistent during the collaborative phase and individual posttest phase. The rationale for this hypothesis was due to the fact that collaboration was expected to be beneficial to everyday problem-solving performance, particularly for older adults (e.g., Dixon \& Gould, 1998; Margrett \& Marsiske, 2005). The hypothesized results were not supported in males or females.

Due to the extant literature emphasizing the positive aspects of collaboration across the lifespan, it was surprising to find that collaboration did not significantly boost younger, middleaged, and older everyday problem-solving performance. In fact, the patterns were different for males and females.

Although the age differences for males and females were in the predicted direction as previous research (e.g., younger outperforming older at various occasions), age differences in the current study were expected to be less pronounced during collaboration compared to the initial individual phase of problem solving. Older males who collaborated actually generated substantially fewer solutions compared to pretest individual performance; thus leading to the significant age differences in the performance outcome on the EPSI. Younger females produced fewer solutions during collaboration than the individual pretest assessment; thus decreasing the significant age differences found during pretest.

Perhaps the reason for the age differences during collaboration was due to the nature of the scoring (i.e., fluency of safe and effective solutions). Overall, female performance slightly declined during collaboration while older adult male performance substantially declined. Perhaps this decline in fluency is due to some participants choosing the most efficient solutions to write down when they worked with their partner. Some may argue that the number of generated solutions is less important than finding one efficient solution that resolves the problem (Thornton 
\& Dumke, 2005). Therefore, if some participants are adapting this particular strategy, they may appear to be less capable problem-solvers in terms of fluency, as was assessed in the current study. Whether older adults are trying to generate only the best possible solutions rather than exhausting all possibilities is unknown in the current study; however the next major section will discuss a different scoring method (i.e., efficiency proportion score) to explore this inquiry.

\section{Group Differences in Efficiency}

It was expected that similar patterns of results would be found when examining fluency and efficiency. The results of the study did not support this hypothesis because very different patterns of findings emerged for the efficiency proportion score compared to scoring the EPSI based on fluency. Despite the findings for this research question, it should be noted that the sample as a whole produced efficient solutions: .94, .92, and .93 (out of a possible 1.00) for Phase 1, 2, and 3, respectively. This finding suggests that participants were abiding by the directions and only generating safe and effective solutions to the hypothetical vignettes. It also suggests that the participants performed at their maximal potential, minimizing the chance of reliable improvement from collaboration. Explanations for the significant Age Group x Gender interaction and the Age Group x Condition trend are described below.

Age Group x Gender interaction. When scores were collapsed across condition and phase, older males produced more efficient responses than younger males. There were no age differences for female responses. Due to the fact that this type of scoring in everyday problemsolving research was not previously examined, other possible individual differences between older and younger males are not known. Based on observations made during testing sessions and completed protocols, one hypothesis for this difference could be due to older males consciously producing efficient responses, whereas younger males might have generated a number of 
solutions that were not considered safe and effective. It is unknown whether these younger males did not take the protocol seriously (based on a few fanciful answers) or if these were actual solutions that this cohort would utilize in real life (e.g., more aggressive solutions).

Age Group x Problem-Solving Condition interaction. Collapsed across gender and phase, there were no age differences in the control condition. This is similar to the findings reported for the fluency scoring method. In the experimental condition, older adults outperformed younger adults. Due to the fact that the experimental condition consisted of both individual and collaborative performances, it is difficult to fully understand the age difference (i.e., whether collaboration differentially affected younger or older adults).

Another explanation might be due to older adults accumulating knowledge based on experience with social tasks. Cornelius and Caspi (1987), for example, found that older adults performed better on the EPSI (closed-version) compared to younger adults. In their discussion, Cornelius and Caspi mention that perhaps there is an increase in everyday problem solving across the life span due to experience and accumulated knowledge with everyday life tasks. In their study, this particular age difference was based on ratings of potential solutions, so participants were not generating their own solutions. In other studies, an open-ended version of the EPSI was used (e.g., Margrett, 1999; Marsiske \& Willis, 1995, Blanchard-Fields et al., 2004). Age comparison findings on open-ended or "ill-structured" tasks where the number of generated solutions is the scoring method used demonstrate that younger adults typically outperform older adults. Perhaps, the additional scoring method in the current study is more beneficial to older adults because they are able to generate better quality responses than younger adults (Gould et al., 2002) and tend to minimize details (e.g., leave out less efficient solutions). 
In order to present more conclusive explanations for these findings, additional studies examining age differences in everyday problem solving scoring need to be conducted.

\section{Individual Change in Fluency}

In an attempt to elucidate group differences, individual reliable change was examined. It was expected that the majority of individuals would improve (as a result of collaboration or practice) and very few participants would decline. This hypothesis was partially supported. Few participants in the study improved or declined and the majority of the participants remained stable. In the discussion of the efficiency score above, it was noted that participants were performing very well (i.e., high efficiency scores). Therefore, if participants were performing at optimal levels at baseline, room for reliable improvement would be minimal and chances of decline (regression to the mean, fatigue) would be more likely. The results for this particular research question are best explained by ceiling effects.

Unfortunately, it was difficult to determine how the findings for individual-level change related to the findings for group differences because performances at each phase were not statistically compared at the group level. Although the results for the dyadic data suggested that collaboration was not necessarily beneficial, the individual-level data suggest that some participants did improve, particularly in the experimental condition, and most participants remained stable. Therefore, at a minimum, the fact that the majority of participants remained stable highlights the fact that collaboration was not detrimental.

\section{Predicting Group Status}

The most relevant investigation of factors that affect collaborative everyday problem solving in adulthood was conducted by Margrett \& Marsiske (2005). They found that gender, the presence of a partner, and the type of task completed could affect everyday problem-solving 
performance. Based on the findings of prior work, it was expected that various factors would be predictive of everyday problem solving; however the relation of these factors to individual reliable change (improvement, stability, decline) was exploratory. Differential patterns of predictors were found based on the two particular time points examined. The patterns of results are discussed below.

Phase 1 to Phase 2. The finding that individuals who scored the highest on the cognitive function (i.e., inductive reasoning, advanced vocabulary, education) experienced the most decline was intriguing. One hypothesis for this finding could be that individuals with higher cognitive abilities, when paired up with a potentially less-skilled partner, suffer from collaboration. Another possible explanation is that those with higher cognitive abilities are capable of thoroughly processing the information, and thus only write down solutions that are considered to be the most efficient. Furthermore, individuals who scored the lowest on the cognitive function tended to remain stable in performance. One hypothesis for this finding is that individuals with lower cognitive capacity may have a more difficult time collaborating due to the deficient ability to attend to multiple stimuli. Additionally, if the individuals with lower cognitive scores are working with a more advanced partner, less collaboration may occur and the individual continues at their own pace, mimicking individual performance.

Phase 2 to Phase 3. The current findings suggest that those with higher means in marital conflict and education were more likely to experience decline after collaboration. In terms of education, a similar interpretation as above would best explain this finding. The finding that higher marital conflict predicted Phase 2 to Phase 3 decliners was in-line with interpretation. Perhaps individuals who experience more conflict in their marriage do not collaborate to the extent of 
those who are happily married or perhaps these individuals discard suggestions from their spouse.

Phase 1 to Phase 3. The finding that marital satisfaction, marital duration, and age significantly related to classification status is unclear. Individuals who either improved or declined scored lower on this function. Younger individuals, who have not been married long, and who experience lower marital satisfaction, tend to either improve or decline from pretest to posttest. One hypothesis is that individual differences that were not examined in the study explain improvement or decline in this group of individuals. Based on what was previously mentioned about younger males (i.e., did not take protocol seriously), some younger adults could have improved because they were interested in accurate participation whereas other younger individuals generated unrealistic responses.

\section{Limitations and Future Directions}

Some caveats should be considered when interpreting the results of the current study. First, participants were performing at exceptional levels during baseline, leaving little room for reliable improvement. This ceiling effect could have been due to the nature of the task, the nature of the sample, or the scoring methods used. Examining problem solving on a variety of tasks using different scoring methods in a more heterogeneous sample is needed.

Another limitation of the current study was that the collaborative interactive process, which appears to affect collaborative outcome (e.g., Kimbler \& Margrett, 2005a), was not examined. In order to better understand the nature of collaboration (e.g., gender differences, age differences, "couples' expertise"), the process of working with a partner needs to be examined as well. 
There are also issues related to sample size with the four-way design. When interpreting the significant four-way interaction in the current study, cell sizes were often small. Therefore, it is likely that there was not sufficient power to detect significant effects, increasing the likelihood of making a Type 2 error. Future studies that wish to examine several factors as they relate to everyday problem solving or collaborative cognition should take power into consideration because due to the complexity of these phenomena, higher order interactions are likely to occur.

Lastly, one concern in the gerontological literature is maintaining functioning and independence in later life. To target this interest more thoroughly, the subfield of cognitive aging must examine the developmental trajectory of everyday problem in adulthood. In the current study, only age differences can be discussed. To understand age change, longitudinal designs, which assess everyday cognition across adulthood, must be conducted. If these designs were implemented, there would be a broader understanding of basic cognitive abilities, everyday cognition, and how the two relate, which is much needed in the literature.

\section{Conclusions}

The current study contributed to the everyday problem-solving and collaborative literature in several ways. First, the complex findings suggest the need for further research in the areas of everyday problem solving and collaboration and that we cannot yet assume that older adults are less capable problem solvers compared to their younger counterparts, especially in everyday tasks. For example, the current study found differential patterns of age differences based on two different scoring methods on the same task (i.e., the EPSI). For the most part, younger adults seem to do better in fluency, whereas older adults appear to perform better in terms of efficiency. This finding should be considered when designing everyday problem-solving studies that examine age differences because the scoring method used could mask or increase 
differences between age groups (e.g., Thornton \& Dumke, 2005). Overall, the findings of this study suggest that it is not singly age, gender, or collaboration that matters but rather the synergistic effect of all factors is important to the understanding of how people approach interpersonal problem solving. Hopefully, these findings will motivate social cognition researchers to further explore these factors.

Another contribution of this study is theoretical. One theoretical approach outlined in the current literature suggests that the experience and knowledge accumulated in older adulthood help to preserve everyday cognitive abilities in later life (Baltes, 1993; Cornelius \& Caspi, 1987). Another theoretical approach suggests that there is a linear decline in everyday functioning with age (Marsiske \& Willis, 1995; Heidrich \& Denney, 1994). The current study shows support for both positions. There were very few significant age differences in everyday problem-solving across the phases, yet at times, younger adults outperformed older adults. Furthermore, although some studies highlight that everyday performance peaks in middle adulthood, there were mixed results in the current study with older adults demonstrating optimal performance at times. Furthermore, the current study did not find support for the premise that basic cognitive abilities significantly relate to everyday performance outcome, emphasizing the need to further explore the multidimensionality of collaborative everyday problem solving. Due to the complexity of the current findings, it only supports the fact that longitudinal research needs to be conducted to examine a trajectory of everyday problem solving across the adult life span. Doing so would add to our understanding of the nature of the factors examined in the current study.

This current study also contributed to the beginning of understanding patterns between husbands' and wives' everyday problem solving and collaborative outcome. Few studies have examined gender differences in everyday problem solving and collaboration between adult males 
and females. This study illustrated that the patterns of everyday problem solving and collaboration were quite different for males and females. Future studies should examine gender differences in terms of different types of scoring methods and tasks, as one sex may be more influential than the other during collaboration on certain types of everyday tasks (Margrett \& Marsiske, 2002).

Lastly, the current study examined everyday problem solving and collaboration at both the group and the individual level. From the findings, it appears that design factors might be more important than individual characteristics; however individual characteristics (e.g., cognitive ability) as well as dyadic characteristics (martial quality, martial length) also play an important role in everyday problem solving across time (Margrett \& Marsiske, 2005). Studies that focus on these factors are important to conduct in order to better understand the nature of everyday problem solving across different domains and designs. Although the current study cannot provide a clear answer for what are the most important determinants of successful problem solving and likelihood of performance change (e.g., collaboration or individual performance, age, gender, cognitive ability, marital quality), it does provide support for some factors (e.g., gender, age, cognitive ability, marital qualities) that appear to be related to everyday problem solving and collaboration. Future studies that tease apart these factors in more focused studies, which will allow isolation of potentially influential factors, may help researchers better understand this interesting yet complex process. 


\section{References}

Allaire, J.C., \& Marsiske, M. (1999). Everyday cognition: Age and intellectual ability correlates. Psychology and Aging, 14, 627-644.

Andersson, J., \& Rönnberg, J. (1995). Recall suffers from collaboration: Joint recall effects of friendship and task complexity. Applied Cognitive Psychology, 9, 199-211.

Andersson, J., \& Rönnberg, J. (1996). Collaboration and memory: Effects of dyadic retrieval on different memory tasks. Applied Cognitive Psychology, 10, 171-181.

Bäckman, L., \& Dixon, R.A. (1992). Psychological compensation: A theoretical framework. Psychological Bulletin, 112, 259-283.

Ball, K., Berch, D.B., Helmers, K.F., Jobe, J.B., Leveck, M.D., Marsiske, M., Morris, J.N., Rebok, G.W., Smith, D.M., Tennstedt, S.L., Unverzagt, F.W., \& Willis, S.L. (2002). Effects of cognitive training interventions with older adults: A randomized controlled trial. Journal of the Medical Association, 288, 2271-2281.

Baltes, P.B. (1993). The aging mind: Potentials and limits. Gerontologist, 33, 580-594.

Berg, C.A., Johnson, M.M.S., Meegan, S.P., \& Strough, J. (2003). Collaborative problemsolving interactions in young and old married couples. Discourse Processes, 15, 33-58.

Blanchard-Fields, F., Stein, R., \&Watson, T.L. (2004). Age differences in emotion-regulation strategies in handling everyday problems. Journal of Gerontology: Psychological Sciences, 59B, P261-P269.

Braiker, H.B., \& Kelley, H.H. (1979). Conflict in the development of close relationships. In R.L. Burgess \& T.L. Huston (Eds.). Social exchange in developing relationships (pp. 135168). New York: Academic Press. 
Campbell, L., \& Kashy, D.A. (2002). Estimating actor, partner, and interaction effects for dyadic data using PROC MIXED and HLM: A user-friendly guide. Personal Relationships, 9, $327-342$.

Carstensen, L.L., Levenson, R.W., \& Gottman, J.M. (1995). Emotional behavior in long-term marriage. Psychology and Aging, 10, 140-149.

Chinn, P.W.U., Mãnoa, H.I., Hilgers, T.L. (2000). From corrector to collaborator: The range of instructor roles in writing-based natural and applied science classes. Journal of Research in Science Teaching, 37, 3-25.

Cornelius, S.W., \& Caspi, A. (1987). Everyday problem solving in adulthood and old age, Psychology and Aging, 2, 144-153..

De Lisi, R., \& Golbeck, S.L. Implications of Piagetian Theory for Peer Learning. In A.M. O’Donnel \& A. King (Eds.), Cognitive Perspectives on Peer Learning. Mahwah, NJ: Lawrence Erlbaum Associates.

Denney, N.W., \& Heidrich, S.M. (1990). Training effects on Raven's Progressive Matrices in young, middle-aged, and elderly adults. Psychology and Aging, 5, 144-145.

Denney, N.W., \& Pearce, K.A. (1989). A developmental study of practical problem solving in adults. Psychology and Aging, 4, 438-442.

Denney, N.W., Pearce, K.A., \& Palmer, A.M. (1982). A developmental study of adults' performance on traditional and practical problem-solving tasks. Experimental Aging Research, 8, 115-118.

Diehl, M., Willis, S.L., \& Schaie, K.W. (1995). Everyday Problem Solving in Older Adults: Observational Assessment and Cognitive Correlates. Psychology and Aging, 10, 478-491. 
Dixon, R.A., \& Bäckman, L. (Eds.). (1995). Compensating for psychological deficits and declines: Managing losses and promoting gains. Mahwah, NJ: Lawrence Erlbaum Associates, Inc.

Dixon, R.A., \& Gould, O.N. (1996). Adult telling and retelling stories collaboratively. In P.B. Baltes \& U.M. Staudinger (Eds.), Interactive Minds: Life-span perspective on the social foundation of cognition. New York: University Press.

Dixon, R.A., \& Gould, O.N. (1998). Younger and older adults collaborating on retelling everyday stories. Applied Developmental Science, 2, 160-171.

Dudek, F.J. (1979). The continuing misinterpretation of the standard error of measurement. Psychological Bulletin, 86, 335-337.

Ekstrom, R. B., French, J. W., Harman, H. H. \& Dermen, D. (1976). Manual for kit of factorreferenced cognitive tests. Princeton, NJ: Educational Testing Service.

Fleming, V.M., \& Alexander, J.M. (2001). The benefits of peer collaboration: A replication with a delayed posttest. Contemporary Educational Psychology, 26, 588-601.

Freund, A.M., \& Baltes, P.B. (1998). Selection, optimization, and compensation as strategies of life management: Correlations with subjective indicators of successful aging. Psychology and Aging, 13, 531-543.

Freund, A.M., \& Baltes, P.B. (2002). Life-management strategies of selection, optimization, \& compensation: Measurement by self-report and construct validity. Journal of Personality and Social Psychology, 82, 642-662.

Garton, A.F., \& Pratt, C. (2001). Peer assistance in children's problem solving. British Journal of Developmental Psychology, 19, 307-318. 
Gauvain, M., \& Rogoff, B. (1989). Collaborative problem solving and children's planning skills. Developmental Psychology, 25, 139-151.

Glick, P.C., \& Spanier, G.B. (1980). Married and unmarried cohabitation in the United States. Journal of Marriage and the Family, 42, 19-30.

Golbeck, S.L. (1998). Peer collaboration and children's representation of the horizontal surface of liquid. Journal of Applied Developmental Psychology, 19, 571-592.

Gould, O.N., \& Dixon, R.A. (1993). How we spent our vacation: Collaborative story-telling by young and old adults. Psychology and Aging, 8, 10-17.

Gould, O.N., Kurzman, D., \& Dixon, R.A. (1994). Communication during prose recall conversations by young and old dyads. Discourse Processes, 17, 149-165.

Gould, O.N., Osborn, C., Krein, H., \& Mortenson, M. (2002). Collaborative recall in married and unacquainted dyads. Collaboration in later life [Special Issue]. International Journal of Behavioral Development, 26, 36-44.

Gould, O.N., Trevithick, L., \& Dixon, R.A. (1991). Adult age differences in elaborations produced during prose recall. Psychology and Aging, 6, 93-99.

Hart, L.C. (1993). Some factors that impede or enhance performance in mathematical problem solving. Journal for Research in Mathematics Education, 24, 167-171.

Hart, J.W., Bridgett, D.J., \& Karau, S.J. (2002). Coworker ability and effort as determinants of individual effort on a collective task. Group Dynamics: Theory, Research, and Practice, 5, 181-190.

Heidrich, S.M., \& Denney, N.W. (1994). Does social problem solving differ from other types of problem solving during the adult years? Experimental Aging Research, 20, 105-126. 
Keppel, G. (1991). Design and analysis: A researcher's handbook (3 ${ }^{\text {rd }}$ ed.). New Jersey: Prentice Hall.

Kimbler, K.J., \& Margrett, J.A. (2005a). Older adults' verbal behaviors during collaboration on everyday problems: Linking process and outcome. Manuscript submitted for publication.

Kimbler, K.J., \& Margrett, J.A. (2005b). Assessment of marital quality: Use of the Relationship Questionnaire in long-term married couples. Manuscript in preparation.

Kotkin, M. (1983). Sex roles among married and unmarried couples. Sex Roles, 9, 975-985.

Lawton, M.P., \& Brody, E. (1969). Assessment of older people: Self-maintaining and instrumental activities of daily living. The Gerontologist, 9, 179-186.

Light, P., Little, K., Bale, S., Joiner, R., Messer, D. (2000). Gender and social comparison effects in computer-based problem solving. Learning and Instruction, 10, 483-496.

Maccoby, E.E. (2000). Perspectives on gender development. International Journal of Behavioral Development, 24, 398-406.

Margrett, J.A. (1999). Collaborative cognition and aging: A pilot study. Unpublished doctoral dissertation, Wayne State University.

Margrett, J.A., \& Marsiske, M. (2002). Gender differences in older adults' everyday cognitive collaboration. Collaboration in later life [Special Issue]. International Journal of Behavior Development, 26, 45-59.

Margrett, J.A., \& Marsiske, M. (2005). Collaboration on everyday problem-solving tasks by older adults. Manuscript submitted for publication.

Margrett, J.A., \& Willis, S.L. (in press). In-home cognitive training with older married couples: Individual versus collaborative learning. Aging, Neuropsychology, and Cognition. 
Marsiske, M., \& Willis, S.L. (1995). Dimensionality of everyday problem solving in older adults. Psychology and Aging, 10, 269-283.

McHale, S.M., Freitag, M.K., \& Crouter, A.C. (1991). Connections between dimensions of marital quality and school-age children's adjustment. Journal of Applied Developmental Psychology, 12, 1-17.

Meegan, S.P., \& Berg, C.A. (2002). Contexts, functions, form, and processes of collaborative everyday problem solving in older adulthood. Collaboration in later life [Special Issue]. International Journal of Behavioral Development, 26, 6-15.

Moss, K. (2003). Examination of effective and ineffective collaborative techniques in older adult dyads. Unpublished honors thesis, West Virginia University.

Nettles, E.J., \& Loevinger, J. (1983). Sex role expectations and ego level in relation to problem marriages. Journal of Personality and Social Psychology, 45, 676-687.

Ocker, R.J., \& Yaverbaum, G.J. (1999). Asynchronous computer-mediated communication variables face-to-face collaboration: Results on student learning, quality and satisfaction. Group Decision and Negotiation, 8, 427-440.

Pfeffer, R.I., Kurosaki, T.T., Harrah, C.H., Chance, J.M., \& Filos, S. (1982). Measurement of functional activities in older adults in the community. Journal of Gerontology, 37, 323329.

Rogoff, B. (1998). Cognition as a collaborative process. In W. Damon (Series Ed.), D. Kuhn \& R.S. Siegler, (Vol. Eds.), Handbook of child psychology: Vol 2. Cognition, perception, and language (5 $5^{\text {th }}$ ed., pp. 679-744). New York: Wiley. 
Rusbult, C. E., Arriaga, X. B., \& Agnew, C. R. (2001). Interdependence in close relationships. In. G. J. Fletcher \& M. S. Clark (Eds.), Blackwell handbook of social psychology: Interpersonal processes (pp. 259-387). Malden, MA: Blackwell.

Salthouse, T.A. (1996). The processing speed theory of adult age differences in cognition. Psychological Review, 103, 403-428.

Salthouse, T.A. \& Babcock, R.L. (1991). Decomposing adult age differences in working memory. Developmental Psychology, 27, 763-776.

Scanlon, E. (2000). How gender influences learners working collaboratively with science simulations. Learning and Instruction, 10, 463-483.

Schafer, J.L., \& Graham, J.W. (2002). Missing data: Our view of the state of the art. Psychological Methods, 7, 147-177.

Schaie, K.W. (1989a). The hazards of cognitive aging. The Gerontologist, 29, 484-493.

Schaie, K.W. (1989b). Perceptual speed in adulthood: Cross-sectional and longitudinal studies. Psychology and Aging, 4, 443-453.

Schaie, K.W. (1993). The Seattle Longitudinal Studies of Adult Intelligence. American Psychology Society, 2, 171-175.

Schaie, K.W. (2000). The impact of longitudinal studies on understanding development from young adulthood to old age. International Journal of Behavioral Development, 3, 257 266.

Schaie, K.W., \& Willis, S.L. (1999). Theories of everyday competence and aging. In V.L. Bengston \& K.W. Schaie (Eds.), Handbook of theories of aging (pp. 174-195). New York: Springer Publishing Company. 
Smith, T.W., Gallo, L.C., Goble, L., Ngu, L.Q., \& Stark, K.A. (1998). Agency, communion, and cardiovascular reactivity during marital interaction. Health Psychology, 17, 537-545.

Spanier, G.B. (1976). Measuring dyadic adjustment: New scales for assessing the quality of marriage and similar dyads. Journal of Marriage and the Family, 38, 15-28.

Staudinger, U.M., \& Baltes, P.B. (1996). Interactive minds: A facilitative setting for wisdom-related performance? Journal of Personality and Social Psychology, 71, 746762.

Stoyanova, H., Kommers, P. (2002). Concept mapping as a medium of shared cognition in computer-supported collaborative problem solving. Journal of Interactive Learning Research, 13, 111-133.

Strough, J. \& Margrett, J. (2002). Overview of the special section on collaborative cognition in later adulthood. International Journal of Behavioral Development, 26, 2-5.

Tabachnick, B.G., \& Fidell, L.S. Using multivariate statistics (4 ${ }^{\text {th }}$ ed.). Boston: Allyn and Bacon. Thornton, W.J.L., \& Dumke, H.A. (2005). Age differences in everyday problem-solving and decision-making effectiveness: A meta-analytic review. Psychology and Aging, 20, 8599.

Thurstone, T.G. (1962). Primary Mental Ability for Grades 9-12 (Rev. ed.). Chicago, IL: Science Research Associates.

Tudge, J., \& Winterhoff, P. (1993). Can young children benefit from collaborative problem solving? Tracing the effects of partner competence and feedback. Social Development, 2 , 242-259.

US Census Bureau (2005, February). Number, Timing, and Duration of Marriages and Divorces: 2001. Retrieved April 14, 2005: http://www.census.gov/prod/2005pubs/p70-97.pdf 
Vygotsky, L.S. (1978). Mind in society: The development of higher psychological processes. Cambridge, MA: Harvard University Press.

Watson, J.M., \& Chick, H.L. (2001). Factors influencing the outcomes of collaborative mathematical problem solving: An introduction. Mathematical Thinking and Learning, 3, 125-173. 


\section{Footnotes}

${ }^{1}$ Analyses were also conducted with form order entered as a covariate. The four-way interaction remained significant with no main effects or lower order interactions, $F(4,78)=2.54, p<.05, \eta$ $=.12$. All subsequent analyses were performed without form order as a covariate, as it made no difference in the outcome.

${ }^{2}$ Analyses were also conducted with form order entered as a covariate. The Gender x Age Group interaction remained significant, $F(2,76)=4.81, \mathrm{p}<.05, \eta=.20$, and the Condition $\mathrm{x}$ Age Group interaction remained a trend, $F(2,38)=3.18, \mathrm{p}=.05, \eta=.14$. All subsequent analyses were performed without form order as a covariate, as it made no difference in the outcome. 
Table 1

Descriptive Statistics of Background and Outcome Variables by Age Group

\begin{tabular}{|c|c|c|c|c|c|c|c|c|c|c|}
\hline \multirow[b]{2}{*}{ Variable } & \multirow[b]{2}{*}{$N$} & \multicolumn{3}{|c|}{ Younger Adults } & \multicolumn{3}{|c|}{ Middle-Aged Adults } & \multicolumn{3}{|c|}{ Older Adults } \\
\hline & & $M$ & $S D$ & Range & $M$ & $S D$ & Range & $M$ & $S D$ & Range \\
\hline $\operatorname{Age}^{d}$ & 90 & $25.73^{\mathrm{a}, \mathrm{b}}$ & 3.33 & $20.74-33.71$ & $45.95^{\mathrm{a}, \mathrm{c}}$ & 4.78 & $35.43-56.69$ & $75.29^{b, c}$ & 6.83 & $64.45-86.88$ \\
\hline Education $^{\mathrm{d}}$ & 89 & $16.47^{\mathrm{a}, \mathrm{b}}$ & 1.87 & $12.00-20.00$ & $14.90^{\mathrm{a}}$ & 2.28 & $12.00-21.00$ & $14.66^{\mathrm{b}}$ & 2.53 & $11.00-21.00$ \\
\hline Marital Length $^{\mathrm{d}}$ & 90 & $2.40^{\mathrm{a}, \mathrm{b}}$ & 2.24 & $0.16-8.39$ & $16.03^{\mathrm{a}, \mathrm{c}}$ & 9.07 & $1.15-31.98$ & $4.00^{\mathrm{b}, \mathrm{c}}$ & 16.21 & $6.39-63.23$ \\
\hline Median Income ${ }^{d}$ & 85 & $26000^{\mathrm{a}, \mathrm{b}}$ & - & $\begin{array}{l}5000- \\
50000\end{array}$ & $50000^{\mathrm{a}, \mathrm{c}}$ & - & $\begin{array}{c}29000- \\
50000\end{array}$ & $40000^{\mathrm{b}, \mathrm{c}}$ & - & $\begin{array}{l}13000- \\
50000\end{array}$ \\
\hline Physical Health $^{\mathrm{d}}$ & 90 & 2.13 & 0.63 & $1.00-4.00$ & 1.97 & 0.72 & $1.00-3.00$ & 2.13 & 0.67 & $1.00-4.00$ \\
\hline Mental Health $^{\mathrm{d}}$ & 90 & 1.83 & 0.65 & $1.00-3.00$ & 1.73 & 0.58 & $1.00-3.00$ & 1.63 & 0.67 & $1.00-3.00$ \\
\hline Vocabulary $^{\mathrm{d}}$ & 90 & 25.33 & 3.69 & $17.00-32.00$ & 25.33 & 5.59 & $14.00-35.00$ & 26.47 & 5.60 & $12.00-34.00$ \\
\hline Advanced Vocabulary $^{\mathrm{d}}$ & 90 & 17.63 & 4.46 & $10.00-28.00$ & 18.80 & 5.45 & $10.00-30.00$ & 18.97 & 5.17 & $10.00-30.00$ \\
\hline Perceptual Speed $^{\mathrm{d}}$ & 90 & 25.63 & 4.78 & $19.00-35.00$ & 23.30 & 6.00 & $10.00-34.00$ & 17.63 & 5.74 & $2.00-31.00$ \\
\hline Inductive Reasoning $^{\mathrm{d}}$ & 90 & 23.40 & 4.40 & $13.00-30.00$ & 18.93 & 5.58 & $7.00-30.00$ & 9.30 & 5.03 & $2.00-25.00$ \\
\hline Openness $^{\mathrm{d}}$ & 89 & 3.54 & 0.47 & $2.58-4.33$ & 3.30 & 0.59 & $2.00-4.25$ & 3.13 & 0.45 & $2.42-4.25$ \\
\hline Conscientious $^{\mathrm{d}}$ & 90 & 3.77 & 0.54 & $2.67-4.75$ & 3.84 & 0.50 & $2.75-4.92$ & 3.75 & 0.33 & $3.00-4.42$ \\
\hline Extraversion $^{\mathrm{d}}$ & 89 & 3.29 & 0.47 & $2.42-4.25$ & 3.43 & 0.46 & $2.58-4.42$ & 3.27 & 0.45 & $2.33-4.33$ \\
\hline
\end{tabular}




\begin{tabular}{|c|c|c|c|c|c|c|c|c|c|c|}
\hline \multicolumn{11}{|l|}{ Table 1 (continued) } \\
\hline \multirow[b]{2}{*}{ Variable } & \multirow[b]{2}{*}{$N$} & \multicolumn{3}{|c|}{ Younger Adults } & \multicolumn{3}{|c|}{ Middle-Aged Adults } & \multicolumn{3}{|c|}{ Older Adults } \\
\hline & & $M$ & $S D$ & Range & $M$ & $S D$ & Range & $M$ & $S D$ & Range \\
\hline Agreeableness $^{\mathrm{d}}$ & 90 & 3.78 & 0.52 & $2.58-4.92$ & 3.77 & 0.38 & $2.67-4.75$ & 3.77 & 0.47 & $2.83-4.58$ \\
\hline Neuroticism $^{\mathrm{d}}$ & 89 & 2.54 & 0.67 & $1.08-4.00$ & 2.39 & 0.48 & $1.25-3.58$ & 2.47 & 0.50 & $1.67-3.50$ \\
\hline Love $^{d}$ & 87 & 8.15 & 0.68 & $6.60-9.00$ & 8.26 & 0.72 & $6.20-9.00$ & 8.04 & 0.96 & $5.10-9.00$ \\
\hline Maintenance $^{\mathrm{d}}$ & 88 & $6.55^{\mathrm{b}}$ & 0.94 & $4.20-7.80$ & $6.44^{\mathrm{c}}$ & 1.57 & $2.60-8.60$ & $5.62^{\mathrm{b}, \mathrm{c}}$ & 1.18 & $3.20-8.20$ \\
\hline Ambivalence $^{\mathrm{d}}$ & 90 & $2.51^{\mathrm{a}, \mathrm{b}}$ & 1.51 & $1.00-6.20$ & $1.84^{\mathrm{a}}$ & 0.97 & $1.00-4.40$ & $1.89^{\mathrm{b}}$ & 1.07 & $1.00-6.00$ \\
\hline Conflict $^{\mathrm{d}}$ & 90 & $4.55^{\mathrm{a}, \mathrm{b}}$ & 1.22 & $2.20-6.40$ & $3.81^{\mathrm{a}}$ & 1.24 & $1.60-6.20$ & $3.35^{\mathrm{b}}$ & 1.40 & $1.00-7.80$ \\
\hline \multirow[t]{2}{*}{ Satisfaction $^{\mathrm{d}}$} & 90 & 3.88 & 0.62 & $1.63-4.50$ & 4.10 & 0.49 & $2.75-4.63$ & 4.01 & 0.55 & $2.13-4.63$ \\
\hline & $p$ & \multicolumn{2}{|l|}{$n$} & $\%$ & \multicolumn{2}{|l|}{$n$} & $\%$ & \multicolumn{2}{|l|}{$n$} & $\%$ \\
\hline Ethnicity ${ }^{\mathrm{e}}$ & 0.25 & & & & & & & & & \\
\hline White & & \multicolumn{2}{|l|}{27} & 90.00 & \multicolumn{2}{|c|}{28} & 93.33 & \multicolumn{2}{|c|}{30} & 100.00 \\
\hline African American & & \multicolumn{2}{|l|}{2} & 6.67 & \multicolumn{2}{|c|}{0} & 0.00 & \multicolumn{2}{|c|}{0} & 0.00 \\
\hline Latino & & \multicolumn{2}{|l|}{1} & 3.33 & \multicolumn{2}{|l|}{0} & 0.00 & \multicolumn{2}{|l|}{0} & 0.00 \\
\hline American Indian & & \multicolumn{2}{|l|}{0} & 0.00 & \multicolumn{2}{|l|}{1} & 3.33 & \multicolumn{2}{|l|}{0} & 0.00 \\
\hline Other & & \multicolumn{2}{|l|}{0} & 0.00 & \multicolumn{2}{|l|}{1} & 3.33 & \multicolumn{2}{|l|}{0} & 0.00 \\
\hline
\end{tabular}

Note. ${ }^{\mathrm{a}}$ Younger differs from middle-aged, $p<.05 ;{ }^{\mathrm{b}}$ Younger differs from older, $p<.05 ;{ }^{\mathrm{c}}$ Middle-aged differs from older, $p<.05$. ${ }^{\mathrm{d}} \mathrm{T}$-tests were performed to detect age differences; ${ }^{\mathrm{e}} \mathrm{Chi}$-square tests were performed to detect differences. 
Table 2

Subsample Characteristics by Participation Status

\begin{tabular}{|c|c|c|c|c|c|}
\hline \multirow[b]{2}{*}{ Variable } & \multicolumn{2}{|c|}{$\begin{array}{l}\text { Participated } \\
\qquad(N=89)\end{array}$} & \multicolumn{2}{|c|}{$\begin{array}{l}\text { Non-Participating } \\
\qquad(N=39)\end{array}$} & \multirow[b]{2}{*}{$p$} \\
\hline & $M$ & $S D$ & $M$ & $S D$ & \\
\hline $\mathrm{Age}^{\mathrm{a}}$ & 48.98 & 20.58 & 44.87 & 17.68 & 0.28 \\
\hline Education $^{\mathrm{a}}$ & 15.15 & 2.49 & 15.87 & 1.99 & 0.12 \\
\hline \multirow[t]{2}{*}{ Marriage Length $^{\mathrm{a}}$} & 22.83 & 21.72 & 19.36 & 18.14 & 0.38 \\
\hline & $n$ & $\%$ & $n$ & & \\
\hline Ethnicity $^{\mathrm{b}}$ & & & & & 0.46 \\
\hline White & 84 & 94.4 & 37 & 94.9 & \\
\hline African American & 2 & 2.2 & 0 & 0.0 & \\
\hline Latino & 1 & 1.1 & 0 & 0.0 & \\
\hline American Indian & 1 & 1.1 & 0 & 0.0 & \\
\hline Asian & 1 & 1.1 & 2 & 5.1 & \\
\hline
\end{tabular}

Note. ${ }^{\mathrm{a}}=\mathrm{T}$-tests were conducted to detect differences; ${ }^{\mathrm{b}}=\mathrm{A}$ Chi square test was performed to detect differences

Non-participating status refers to refusals and no-shows. 
Table 3

Subsample Characteristics by Problem-Solving Condition

\begin{tabular}{|c|c|c|c|c|c|}
\hline \multirow[b]{2}{*}{ Variable } & \multicolumn{2}{|c|}{$\begin{array}{l}\text { Control Condition } \\
\qquad(N=30)\end{array}$} & \multicolumn{2}{|c|}{$\begin{array}{l}\text { Experimental Condition } \\
\qquad(N=60)\end{array}$} & \multirow[b]{2}{*}{$p$} \\
\hline & $M$ & $S D$ & $M$ & $S D$ & \\
\hline $\operatorname{Age}^{\mathrm{a}}$ & 50.54 & 21.66 & 48.21 & 20.95 & 0.63 \\
\hline Education $^{\mathrm{a}}$ & 14.73 & 2.15 & 15.66 & 2.41 & 0.08 \\
\hline Income $^{\mathrm{a}}$ & $\$ 36,172$ & $\$ 15,007$ & $\$ 37,759$ & $\$ 12,971$ & 0.62 \\
\hline \multirow[t]{2}{*}{ Marriage Length $^{\mathrm{a}}$} & 21.98 & 21.91 & 22.08 & 22.05 & 0.98 \\
\hline & $n$ & $\%$ & $n$ & $\%$ & \\
\hline Ethnicity ${ }^{\mathrm{b}}$ & & & & & 0.62 \\
\hline White & 30 & 100.00 & 55 & 91.7 & \\
\hline African American & 0 & 0.00 & 2 & 3.3 & \\
\hline Latino & 0 & 0.00 & 1 & 1.7 & \\
\hline American Indian & 0 & 0.00 & 1 & 1.7 & \\
\hline Other & 0 & 0.00 & 1 & 1.7 & \\
\hline
\end{tabular}

Note. ${ }^{\mathrm{a}}=\mathrm{T}$-tests were conducted to detect differences; ${ }^{\mathrm{b}}=\mathrm{A}$ Chi square test was performed to detect differences. 
Table 4

Inter-rater Reliability Checks during Training and Actual Coding

\begin{tabular}{lcccc}
\hline Date & Form 1 & Form 2 & Form 3 & $\begin{array}{c}\text { Average Reliability } \\
\text { (per week) }\end{array}$ \\
\hline Week 1 Practice & 82.1 & 87.1 & $\mathrm{n} / \mathrm{a}$ & 84.3 \\
Week 2 Practice & 83.6 & 83.3 & $\mathrm{n} / \mathrm{a}$ & 83.4 \\
Week 3 Practice & 91.1 & 91.8 & $\mathrm{n} / \mathrm{a}$ & 91.4 \\
Week 1 Study & 95.2 & 90.2 & 96.2 & 92.6 \\
Week 2 Study & 92.0 & 93.2 & 93.3 & 92.7 \\
Week 3 Study & 82.8 & $\mathrm{n} / \mathrm{a}$ & 79.1 & 81.1 \\
Week 4 Study & 93.9 & 84.7 & 82.4 & 84.8 \\
$\begin{array}{l}\text { Total Reliability } \\
\text { for current study }\end{array}$ & 90.9 & 89.4 & 87.8 & 89.4
\end{tabular}

Note. $\mathrm{n} / \mathrm{a}=$ not applicable because Form 3 was created for current study, and there were no overlapped Form 2 protocols during Week 3 
Table 5

Means and Standard Deviations of Younger, Middle-aged, and Older Adults on Problemsolving Performance Outcome

\begin{tabular}{lcccccc}
\hline & $\begin{array}{c}\text { Younger Adults } \\
(n=30 \text { individuals })\end{array}$ & $\begin{array}{c}\text { Middle-aged Adults } \\
(n=30 \text { individuals })\end{array}$ & \multicolumn{2}{c}{$\begin{array}{c}\text { Older Adults } \\
(n=30 \text { individuals })\end{array}$} \\
\cline { 2 - 7 } Outcome Measure & $M$ & $S D$ & $M$ & $S D$ & $M$ & $S D$ \\
\hline Phase 1 Total & 22.73 & 9.33 & 20.75 & 8.03 & 17.36 & 6.99 \\
Phase 2 Total & 21.73 & 8.86 & 20.60 & 7.73 & 15.13 & 6.76 \\
Phase 3 Total & 21.67 & 8.24 & 19.58 & 6.85 & 16.24 & 6.43 \\
Phase 1 Proportion & 0.95 & 0.06 & 0.94 & 0.06 & 0.92 & 0.09 \\
Phase 2 Proportion & 0.91 & 0.07 & 0.92 & 0.06 & 0.94 & 0.10 \\
Phase 3 Proportion & 0.90 & 0.11 & 0.95 & 0.08 & 0.94 & 0.08 \\
\hline
\end{tabular}

Note. Phase refers to the three problem-solving occasions. Total refers to the total number of safe and effective solutions generated. Proportion refers to the total number of safe and effective solutions generated divided by the total overall number of solutions generated. 
Table 6

Analysis of Variance Examining Group Differences in Total Safe and Effective Solutions

\begin{tabular}{|c|c|c|c|c|c|}
\hline Source & $d f$ & $M S$ & $F$ & $\eta$ & $p$ \\
\hline Age Group & 2 & 620.91 & 2.41 & 0.11 & 0.10 \\
\hline Condition & 1 & 19.27 & 19.27 & 0.00 & 0.79 \\
\hline Phase & 2 & 39.92 & 1.34 & 0.07 & 0.28 \\
\hline Gender & 1 & 80.74 & 2.92 & 0.07 & 0.10 \\
\hline Age Group x Condition & 2 & 97.02 & 0.38 & 0.02 & 0.69 \\
\hline Age Group x Phase & 4 & 22.25 & 1.20 & 0.06 & 0.32 \\
\hline Age Group x Gender & 2 & 39.09 & 1.41 & 0.07 & 0.26 \\
\hline Condition $\mathrm{x}$ Phase & 2 & 23.76 & 1.78 & 0.09 & 0.18 \\
\hline Condition x Gender & 1 & 37.13 & 1.34 & 0.03 & 0.25 \\
\hline Phase x Gender & 2 & 64.32 & 2.42 & 0.11 & 0.10 \\
\hline Age Group x Condition x Phase & 4 & 20.84 & 1.30 & 0.06 & 0.28 \\
\hline Age Group x Condition x Gender & 2 & 51.43 & 1.86 & 0.09 & 0.17 \\
\hline Age Group x Phase x Gender & 2 & 13.39 & 0.59 & 0.03 & 0.67 \\
\hline Condition $\mathrm{x}$ Phase $\mathrm{x}$ Gender & 2 & 4.40 & 0.20 & 0.01 & 0.82 \\
\hline Age Group x Condition x Phase x Gender & 4 & 58.30 & 2.65 & 0.12 & 0.04 \\
\hline
\end{tabular}


Table 7

Analysis of Variance Examining Total Safe and Effective Solutions for Males

\begin{tabular}{lccccc}
\hline Source & $d f$ & $M S$ & $F$ & $\eta$ & $p$ \\
\hline Age Group & 2 & 153.59 & 1.16 & 0.06 & 0.32 \\
Condition & 1 & 11.67 & 0.09 & 0.00 & 0.77 \\
Phase & 2 & 2.47 & 0.30 & 0.02 & 0.74 \\
Age Group x Condition & 2 & 8.52 & 0.06 & 0.00 & 0.94 \\
Age Group x Phase & 4 & 12.01 & 1.29 & 0.06 & 0.28 \\
Phase x Condition & 2 & 0.91 & 0.09 & 0.01 & 0.91 \\
Age Group x Condition x Phase & 4 & 48.15 & 5.29 & 0.21 & 0.00 \\
\end{tabular}


Table 8

Estimated Marginal Means for Gender x Condition x Age Group x Phase Interaction Examining Total Safe and Effective Solutions

\begin{tabular}{|c|c|c|c|c|}
\hline Gender & Condition & Age Group & Phase & $M$ \\
\hline \multirow[t]{18}{*}{ Males } & \multirow[t]{9}{*}{ Control } & \multirow[t]{3}{*}{ Younger } & 1 & 19.40 \\
\hline & & & 2 & 20.40 \\
\hline & & & 3 & 22.00 \\
\hline & & \multirow[t]{3}{*}{ Middle-aged } & 1 & 21.32 \\
\hline & & & 2 & 18.40 \\
\hline & & & 3 & 16.88 \\
\hline & & \multirow[t]{3}{*}{ Older } & 1 & 17.00 \\
\hline & & & 2 & 18.08 \\
\hline & & & 3 & 17.32 \\
\hline & \multirow[t]{9}{*}{ Experimental } & \multirow[t]{3}{*}{ Younger } & 1 & 20.40 \\
\hline & & & 2 & 22.20 \\
\hline & & & 3 & 18.80 \\
\hline & & \multirow[t]{3}{*}{ Middle-aged } & 1 & 17.00 \\
\hline & & & 2 & 20.60 \\
\hline & & & 3 & 18.90 \\
\hline & & \multirow[t]{3}{*}{ Older } & 1 & 17.72 \\
\hline & & & 2 & 13.24 \\
\hline & & & 3 & 16.40 \\
\hline \multirow[t]{18}{*}{ Females } & \multirow[t]{9}{*}{ Control } & \multirow[t]{3}{*}{ Younger } & 1 & 20.60 \\
\hline & & & 2 & 21.80 \\
\hline & & & 3 & 20.40 \\
\hline & & \multirow[t]{3}{*}{ Middle-aged } & 1 & 24.60 \\
\hline & & & 2 & 24.60 \\
\hline & & & 3 & 25.20 \\
\hline & & \multirow[t]{3}{*}{ Older } & 1 & 17.00 \\
\hline & & & 2 & 17.20 \\
\hline & & & 3 & 16.20 \\
\hline & \multirow[t]{9}{*}{ Experimental } & \multirow[t]{3}{*}{ Younger } & 1 & 27.80 \\
\hline & & & 2 & 21.90 \\
\hline & & & 3 & 25.00 \\
\hline & & \multirow[t]{3}{*}{ Middle-aged } & 1 & 22.30 \\
\hline & & & 2 & 19.70 \\
\hline & & & 3 & 18.80 \\
\hline & & \multirow[t]{3}{*}{ Older } & 1 & 17.36 \\
\hline & & & 2 & 14.52 \\
\hline & & & 3 & 15.56 \\
\hline
\end{tabular}


Table 9

Analysis of Variance Examining Total Safe and Effective Solutions for Females

\begin{tabular}{lrrrrr}
\hline Source & $d f$ & $M S$ & $F$ & $\eta$ & $p$ \\
\hline Age Group & 2 & 550.74 & 3.17 & 0.14 & 0.05 \\
Condition & 1 & 8.04 & 0.05 & 0.00 & 0.83 \\
Phase & 2 & 32.06 & 0.06 & 0.06 & 0.99 \\
Age Group x Condition & 2 & 182.27 & 1.05 & 0.05 & 0.36 \\
Age Group x Phase & 4 & 1.46 & 0.06 & 0.00 & 0.99 \\
Phase x Condition & 2 & 45.74 & 1.47 & 0.07 & 0.24 \\
Age Group x Condition x Phase & 4 & 9.81 & 0.49 & 0.02 & 0.74 \\
\end{tabular}


Table 10

Analysis of Variance Examining Group Differences in Efficiency Proportion Score

\begin{tabular}{|c|c|c|c|c|c|}
\hline Source & $d f$ & $M S$ & $F$ & $\eta$ & $p$ \\
\hline Age Group & 2 & 0.01 & 0.51 & 0.03 & 0.60 \\
\hline Condition & 1 & 0.02 & 2.72 & 0.07 & 0.11 \\
\hline Phase & 2 & 0.01 & 0.41 & 0.02 & 0.66 \\
\hline Gender & 1 & 2.61 & 0.51 & 0.01 & 0.48 \\
\hline Age Group x Condition & 2 & 0.02 & 3.22 & 0.14 & 0.05 \\
\hline Age Group x Phase & 4 & 1.12 & 1.96 & 0.09 & 0.11 \\
\hline Age Group x Gender & 2 & 2.47 & 4.82 & 0.20 & 0.01 \\
\hline Condition $\mathrm{x}$ Phase & 2 & 3.88 & 0.72 & 0.04 & 0.49 \\
\hline Condition x Gender & 1 & 1.10 & 2.15 & 0.05 & 0.15 \\
\hline Phase x Gender & 2 & 2.04 & 0.36 & 0.02 & 0.70 \\
\hline Age Group x Condition x Phase & 4 & 1.13 & 2.00 & 0.09 & 0.10 \\
\hline Age Group x Condition x Gender & 2 & 4.47 & 0.87 & 0.04 & 0.43 \\
\hline Age Group x Phase x Gender & 4 & 1.01 & 0.18 & 0.01 & 0.95 \\
\hline Condition $\mathrm{x}$ Phase $\mathrm{x}$ Gender & 2 & 5.65 & 0.98 & 0.05 & 0.38 \\
\hline Age Group x Condition x Phase x Gender & 4 & 1.34 & 0.22 & 0.01 & 0.93 \\
\hline
\end{tabular}


Table 11

Estimated Marginal Means for Gender x Age Group Interaction Examining Proportion Score

\begin{tabular}{ccc}
\hline Gender & Age Group & $M$ \\
\hline Male & Younger & 0.91 \\
& Middle-aged & 0.94 \\
& Older & 0.96 \\
\hline Female & Younger & 0.94 \\
& Middle-aged & 0.94 \\
& Older & 0.91 \\
\hline
\end{tabular}


Table 12

Estimated Marginal Means for Problem-Solving Condition x Age Group Interaction Examining Proportion Score

\begin{tabular}{ccc}
\hline Condition & Age Group & $M$ \\
\hline Control & Younger & 0.95 \\
& Middle-aged & 0.95 \\
& Older & 0.93 \\
\hline Experimental & Younger & 0.90 \\
& Middle-aged & 0.93 \\
\hline
\end{tabular}


Table 13

Correlation of Predictor Variables with Discriminant Functions and

Standardized Discriminant Function Coefficients for Phase 1 to Phase 2

\begin{tabular}{lcc}
\hline & $\begin{array}{c}\text { Correlation with } \\
\text { Discriminant } \\
\text { Functions }\end{array}$ & $\begin{array}{c}\text { Standardized } \\
\text { Discriminant } \\
\text { Function Coefficients }\end{array}$ \\
\cline { 2 - 3 } Age & Function 1 & Function 1 \\
Education & 0.12 & 1.54 \\
Marital Length & 0.23 & 0.04 \\
Marital Satisfaction & 0.14 & -0.08 \\
Marital Conflict & -0.02 & -0.33 \\
Advanced Vocabulary & -0.08 & -0.26 \\
Inductive Reasoning & 0.35 & 0.13 \\
\hline
\end{tabular}


Table 14

Correlation of Predictor Variables with Discriminant Functions and Standardized Discriminant Function Coefficients for Phase 2 to Phase 3

\begin{tabular}{|c|c|c|}
\hline & $\begin{array}{l}\text { Correlation with } \\
\text { Discriminant } \\
\text { Functions }\end{array}$ & $\begin{array}{c}\text { Standardized } \\
\text { Discriminant } \\
\text { Function Coefficients }\end{array}$ \\
\hline Predictor Variable & Function 1 & Function 1 \\
\hline Age & -0.39 & 1.53 \\
\hline Education & 0.33 & 0.62 \\
\hline Marital Length & -0.50 & -1.50 \\
\hline Marital Satisfaction & -0.13 & 0.42 \\
\hline Marital Conflict & 0.43 & 0.63 \\
\hline Advanced Vocabulary & -0.38 & -0.91 \\
\hline Inductive Reasoning & 0.29 & 0.25 \\
\hline
\end{tabular}


Table 15

Correlation of Predictor Variables with Discriminant Functions and

Standardized Discriminant Function Coefficients for Phase 1 to Phase 3

\begin{tabular}{|c|c|c|}
\hline & $\begin{array}{l}\text { Correlation with } \\
\text { Discriminant } \\
\text { Functions }\end{array}$ & $\begin{array}{c}\text { Standardized } \\
\text { Discriminant } \\
\text { Function Coefficients }\end{array}$ \\
\hline Predictor Variable & Function 1 & Function 1 \\
\hline Age & 0.26 & -2.02 \\
\hline Education & -0.04 & 0.12 \\
\hline Marital Length & 0.45 & 2.20 \\
\hline Marital Satisfaction & 0.57 & 0.86 \\
\hline Marital Conflict & -0.19 & 0.53 \\
\hline Advanced Vocabulary & 0.16 & 0.22 \\
\hline Inductive Reasoning & -0.21 & -0.51 \\
\hline
\end{tabular}



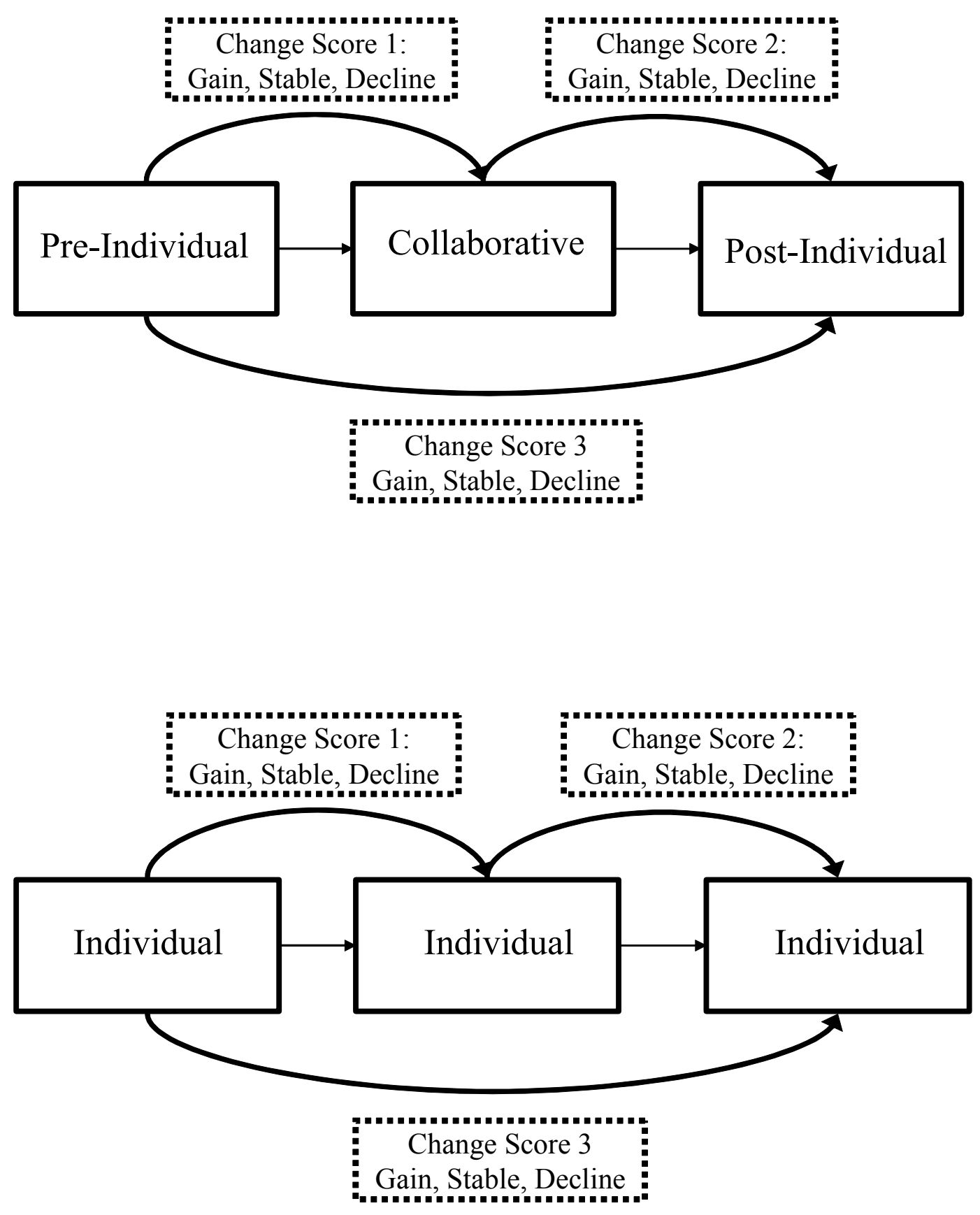


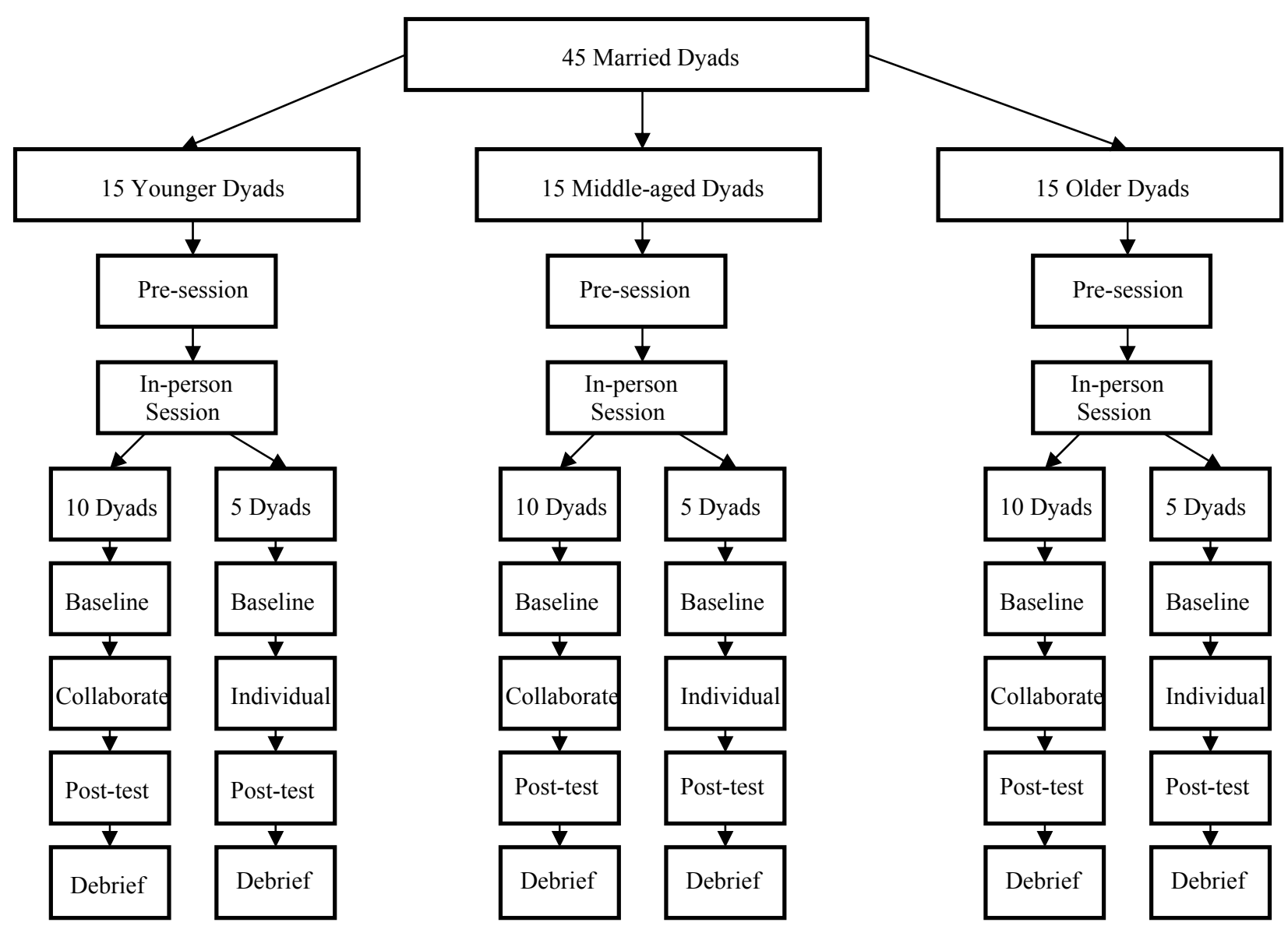


Male Control Condition

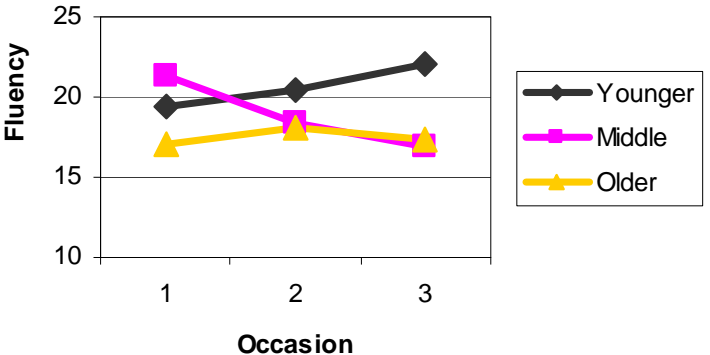

Female Control Condition

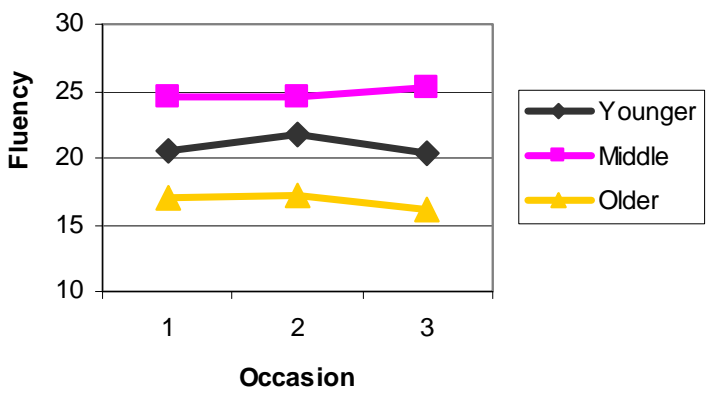

Males Experimental Condition

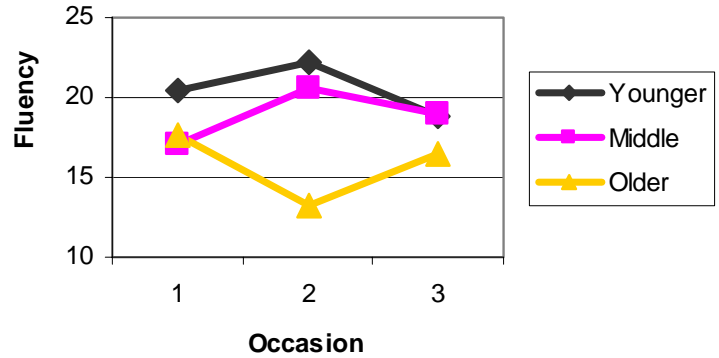

Female Experimental Condition

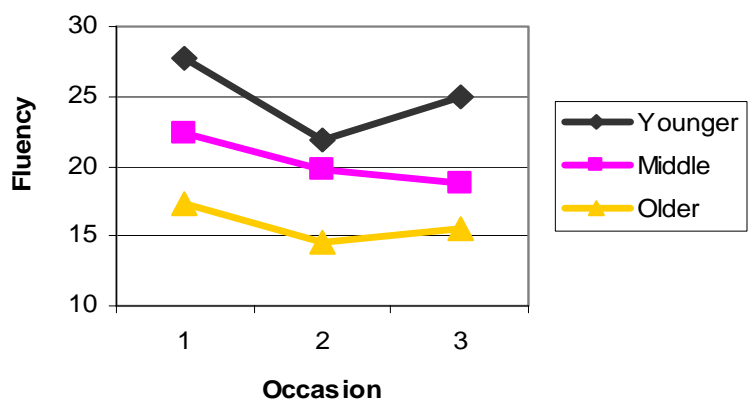




\section{Age Group x Gender}

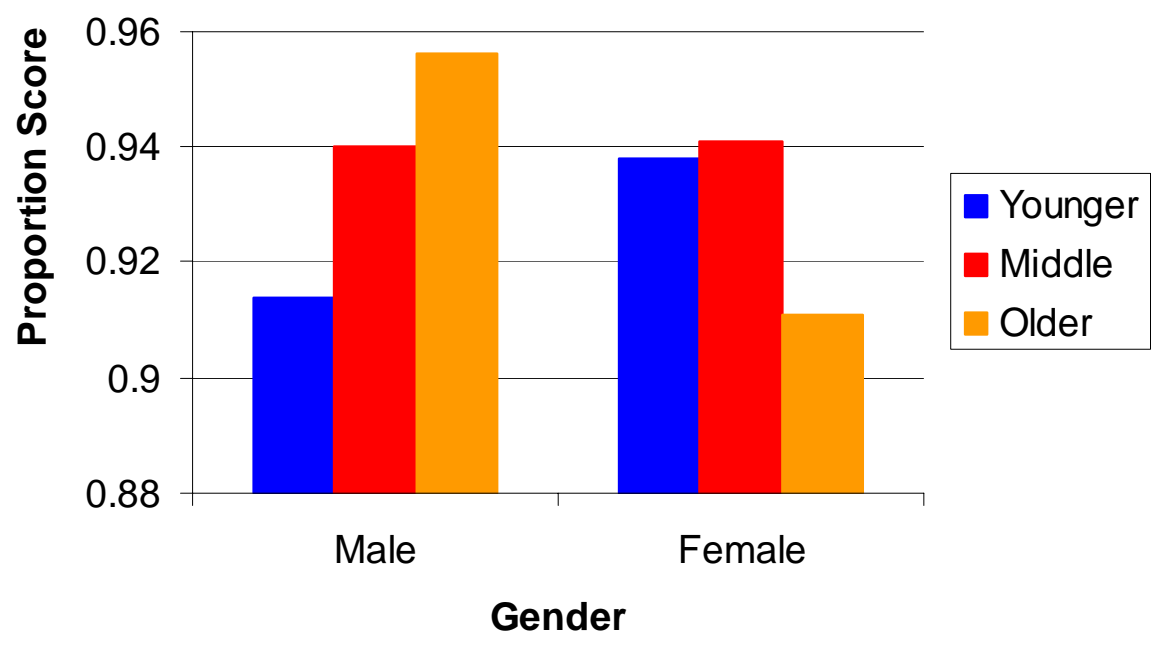


Age Group x Condition

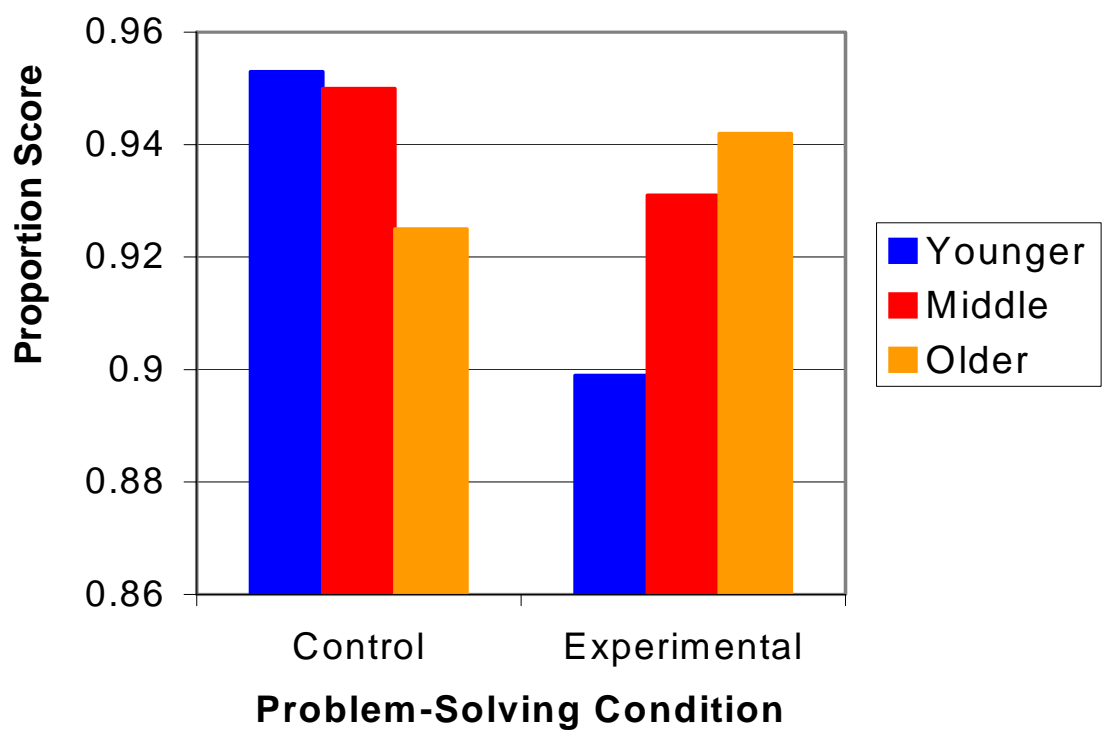




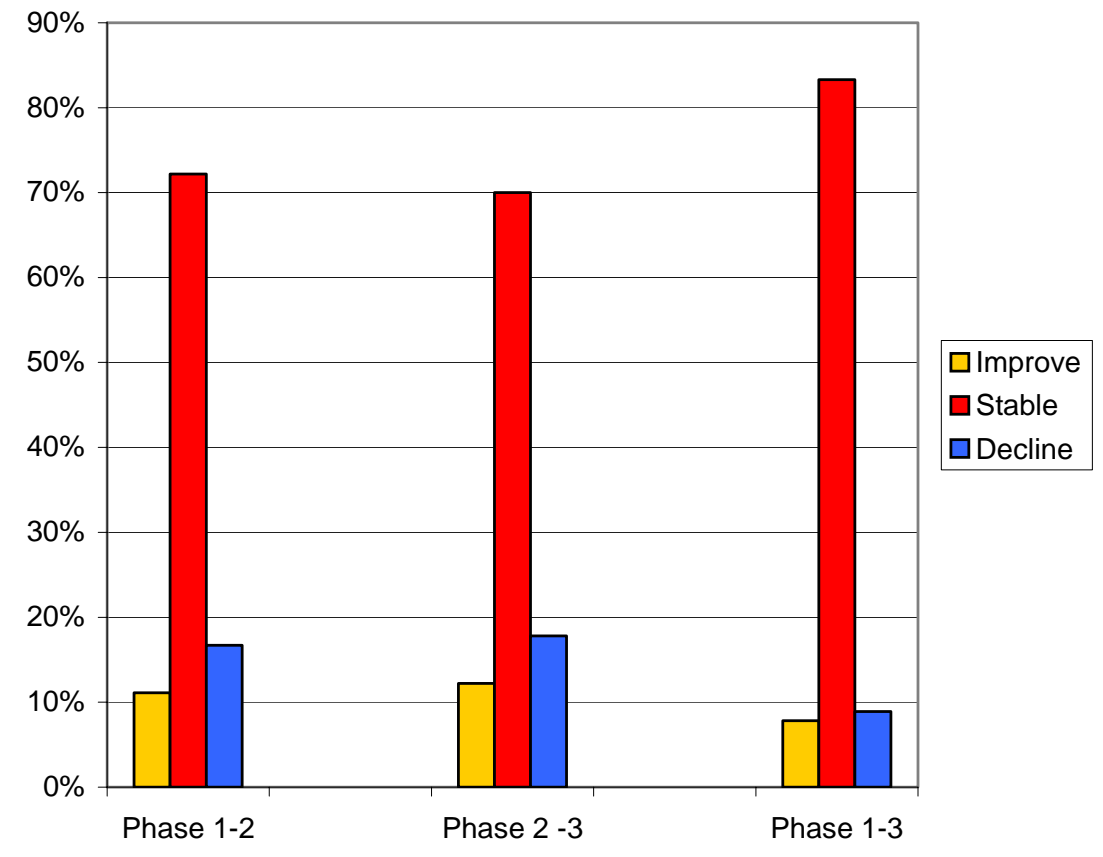


Appendix A: Description of Measures

\begin{tabular}{lll} 
Measure & \multicolumn{1}{c}{ Source } & Construct \\
Personal Data Form & & Demographics \\
Functional Activities Questionnaire & Pfeffer et al., 1982 & Functional Ability \\
Instrumental Activities of Daily Living & Lawton \& Brody, 1969 & ADLs, IADLs \\
NEO-FFI & Costa \& McCrae, 1992 & Personality \\
Number Comparison & Ekstrom et al., 1976 & Perceptual Speed \\
Advanced Vocabulary Test & Ekstrom et al., 1976 & Verbal Ability \\
Vocabulary Test & Ekstrom et al., 1976 & Verbal Ability \\
Letter Series Test & Ekstrom et al., 1976 & Inductive Reasoning \\
Couples Questionnaire & Braiker \& Kelly, 1979 & Marital Quality \\
Dyadic Adjustment Scale (DAS) & Spanier, 1976 & Marital Satisfaction \\
Everyday Problem-Solving Inventory (EPSI) & Cornelius \& Caspi, 1987 & Everyday Cognition \\
\hline
\end{tabular}

Note. ADL $=$ Activities of Daily Living; IADL = Instrumental Activities of Daily Living 
Appendix B

Everyday Problem Solving Inventory Items and Solution Exemplars

\begin{tabular}{|c|c|c|}
\hline Form 1 & Effective Solutions & Ineffective Solutions \\
\hline $\begin{array}{l}\text { Item 1: You lost or broke an } \\
\text { expensive item you borrowed } \\
\text { from someone. }\end{array}$ & $\begin{array}{l}\text { - } \text { Repair } \\
\text { - Apologize } \\
\text { - } \text { Replace } \\
\text { - Confess } \\
\text { - Check with insurance } \\
\text { - } \text { Ompany } \\
\text { - } \\
\text { substitute }\end{array}$ & - Don't tell friend \\
\hline $\begin{array}{l}\text { Item 2: You are shopping for } \\
\text { an item for your home. A } \\
\text { salesman at the store is trying } \\
\text { to sell you a better quality } \\
\text { product, but it is more } \\
\text { expensive than you would like } \\
\text { to pay. }\end{array}$ & $\begin{array}{l}\text { - } \text { Negotiate } \\
\text { - Refuse to buy } \\
\text { - Shop elsewhere } \\
\text { - } \quad \text { Tell salesman the price } \\
\text { you want to pay } \\
\text { - } \\
\text { Ask for another } \\
\text { salesperson }\end{array}$ & $\begin{array}{l}\text { - Tell the salesman to } \\
\text { "bug off" }\end{array}$ \\
\hline $\begin{array}{l}\text { Item 3: You would like to } \\
\text { leave your home at night to } \\
\text { attend a meeting or concert } \\
\text { but are unsure whether it is } \\
\text { safe for you to be out alone. }\end{array}$ & $\begin{array}{l}\text { - } \quad \text { Carry mace } \\
\text { Invite friend/family } \\
\text { member to go along } \\
\text { - Take public } \\
\text { transportation } \\
\text { - Investigate if their is a } \\
\text { daytime substitute } \\
\text { - Let someone know } \\
\text { when you are leaving } \\
\text { and returning }\end{array}$ & $\begin{array}{l}\text { - } \text { Stay home } \\
\text { - Go anyway }\end{array}$ \\
\hline $\begin{array}{l}\text { Item 4: You are doing } \\
\text { something you know perfectly } \\
\text { well how to do by yourself, } \\
\text { and someone begins giving } \\
\text { you advice you neither need } \\
\text { nor want. }\end{array}$ & $\begin{array}{l}\text { - Be polite/patient } \\
\text { - Explain you know } \\
\text { what you are doing } \\
\text { - Tell them you do not } \\
\text { need their help } \\
\text { - Listen and say OK } \\
\text { - Say "Thank You" }\end{array}$ & $\begin{array}{l}\text { - Glare at them like they } \\
\text { are a child }\end{array}$ \\
\hline
\end{tabular}


Appendix B (continued)

\begin{tabular}{|c|c|c|}
\hline Form 1 & Effective Solutions & Ineffective Solutions \\
\hline $\begin{array}{l}\text { Item 5: After you have } \\
\text { finished working hard on a } \\
\text { task or job, your boss } \\
\text { criticizes the way you did it. }\end{array}$ & $\begin{array}{l}\text { - Offer to redo the task } \\
\text { - Ask what you did } \\
\text { wrong } \\
\text { - } \text { Thank boss/Ask for } \\
\text { - } \text { suggestions } \\
\text { - } \text { Listen then explain } \\
\text { frk for suggestions } \\
\text { from coworkers }\end{array}$ & $\begin{array}{l}\text { - } \quad \text { Ignore } \\
\text { - } \quad \text { Feel bad about self }\end{array}$ \\
\hline $\begin{array}{l}\text { Item 6: A family member } \\
\text { behaves in a manner you } \\
\text { dislike very much. }\end{array}$ & $\begin{array}{l}\text { - Talk to them/Ask for } \\
\text { change } \\
\text { - } \text { Take a walk } \\
\text { - } \text { Give constructive } \\
\text { criticism } \\
\text { - } \text { Reinforce them when } \\
\text { they do not engage in } \\
\text { behavior } \\
\text { - Try to understand }\end{array}$ & - Never shout \\
\hline Form 2 & Effective Solutions & Ineffective Solutions \\
\hline $\begin{array}{l}\text { Item 1: You frustrate your co- } \\
\text { workers because you are } \\
\text { slower than they are and hold } \\
\text { things up. }\end{array}$ & $\begin{array}{l}\text { Explain that I'm slow } \\
\text { but thorough } \\
\text { - Work extra hours to } \\
\text { catch up } \\
\text { - Find a different } \\
\text { job/career } \\
\text { - Ask for help }\end{array}$ & $\begin{array}{l}\text { - Co-workers need anger } \\
\text { management training } \\
\text { Do not waste time } \\
\text { thinking about how far } \\
\text { ahead they are }\end{array}$ \\
\hline $\begin{array}{l}\text { Item 2: You are trying to help } \\
\text { a family member who does } \\
\text { not seem to appreciate your } \\
\text { efforts. }\end{array}$ & $\begin{array}{l}\text { Explain why you are } \\
\text { trying to help } \\
\text { - Let them deal with the } \\
\text { problem themselves } \\
\text { - Refer the person to a } \\
\text { helping agency of } \\
\text { some sort }\end{array}$ & $\begin{array}{l}\text { - Help them anyway just } \\
\text { to annoy them } \\
\text { - Don't worry about how } \\
\text { they feel }\end{array}$ \\
\hline
\end{tabular}


Appendix B (continued)

\begin{tabular}{|c|c|c|}
\hline Form 2 & Effective Solutions & Ineffective Solutions \\
\hline $\begin{array}{l}\text { Item 3: You continually } \\
\text { receive mail advertisements } \\
\text { from a firm for products you } \\
\text { do not want and have no } \\
\text { desire of purchasing }\end{array}$ & $\begin{array}{l}\text { - Mark the ads "Return } \\
\text { to sender" } \\
\text { - Put ads in garbage } \\
\text { - Call firm and } \\
\text { complain } \\
\text { - Give information to } \\
\text { someone who would } \\
\text { appreciate the } \\
\text { advertisements }\end{array}$ & $\begin{array}{l}\text { - Don't waste time } \\
\text { responding because } \\
\text { they will continue } \\
\text { - Fill out 'more } \\
\text { information' cards with } \\
\text { fake information }\end{array}$ \\
\hline $\begin{array}{l}\text { Item 4: You are with a group } \\
\text { of people who begin gossiping } \\
\text { about one of your friends. }\end{array}$ & $\begin{array}{l}\text { - Tell them, "I don't } \\
\text { appreciate you talking } \\
\text { about my friend" } \\
\text { - Ask them to switch } \\
\text { topics } \\
\text { - Ask them where they } \\
\text { heard the gossip } \\
\text { - Excuse yourself and } \\
\text { go somewhere else }\end{array}$ & $\begin{array}{l}\text { - Bring up gossip about } \\
\text { them } \\
\text { - Tell the friend } \\
\text { - Tell them people in } \\
\text { glass houses shouldn't } \\
\text { throw stones }\end{array}$ \\
\hline $\begin{array}{l}\text { Item 5: You are trying to reach } \\
\text { a destination in an unfamiliar } \\
\text { area of town and have become } \\
\text { lost while following the } \\
\text { directions you received. }\end{array}$ & $\begin{array}{l}\text { - Call the person who } \\
\text { gave the directions and } \\
\text { ask for clarification } \\
\text { - } \text { Ask someone at a gas } \\
\text { station/business } \\
\text { - } \text { Look at a map } \\
\text { - Retrace my path and } \\
\text { start again, reading the } \\
\text { map carefully }\end{array}$ & $\begin{array}{l}\text { Keep driving around } \\
\text { until you get } \\
\text { somewhere familiar } \\
\text { - Use it as an } \\
\text { opportunity to discover } \\
\text { new areas }\end{array}$ \\
\hline $\begin{array}{l}\text { Item 6: You have some } \\
\text { neighbors with a pet or } \\
\text { children who make so much } \\
\text { noise that it bothers you. }\end{array}$ & $\begin{array}{l}\text { Let the neighbors } \\
\text { know that there is a } \\
\text { problem } \\
\text { - Call the police about a } \\
\text { noise complaint } \\
\text { - Ask them nicely if } \\
\text { they could control the } \\
\text { noise } \\
\text { Turn up the television } \\
\text { so I don't hear them }\end{array}$ & $\begin{array}{l}\text { Threaten their family's } \\
\text { well-being } \\
\text { - Would not go and yell } \\
\text { at neighbor } \\
\text { - Vandalize their } \\
\text { property }\end{array}$ \\
\hline
\end{tabular}




\begin{tabular}{|c|c|c|}
\hline Form 3 & Effective Solutions & Ineffective Solutions \\
\hline $\begin{array}{l}\text { Item 1: Your parent or child } \\
\text { criticizes you for some habit } \\
\text { you have that annoys them. }\end{array}$ & $\begin{array}{l}\text { - Talk with them to } \\
\text { understand the } \\
\text { complaint } \\
\text { - Explain why I might } \\
\text { have the habit } \\
\text { - Work out a } \\
\text { compromise } \\
\text { - Respect their feelings } \\
\text { - Try to change the } \\
\text { behavior }\end{array}$ & $\begin{array}{l}\text { - Do not worry about it } \\
\text { - Tell them to shut up }\end{array}$ \\
\hline $\begin{array}{l}\text { Item 2: You find out that you } \\
\text { have been passed over for a } \\
\text { better job or job promotion } \\
\text { you wanted. }\end{array}$ & $\begin{array}{l}\text { Ask employer the } \\
\text { reasons for selecting } \\
\text { someone else } \\
\text { - Start taking classes, } \\
\text { making you an even } \\
\text { more qualified } \\
\text { candidate } \\
\text { - Send out resumes to } \\
\text { other companies } \\
\text { Cry out your } \\
\text { frustration instead of } \\
\text { bottling it up }\end{array}$ & $\begin{array}{l}\text { - I would feel down at the } \\
\text { moment } \\
\text { - Try not to take it } \\
\text { personally } \\
\text { - Sue them }\end{array}$ \\
\hline $\begin{array}{l}\text { Item } 3 \text { : A complicated form } \\
\text { you completed was returned } \\
\text { because you misinterpreted } \\
\text { the instructions on how to fill } \\
\text { it out. }\end{array}$ & $\begin{array}{l}\text { - } \text { Re-read the } \\
\text { instructions } \\
\text { - Call the place for } \\
\text { clarification and/or } \\
\text { further instructions } \\
\text { - Fill out the form again } \\
\text { - Throw it away in not } \\
\text { important }\end{array}$ & - Don't redo it \\
\hline
\end{tabular}


Appendix B (continued)

\begin{tabular}{|c|c|c|}
\hline Form 3 & Effective Solutions & Ineffective Solutions \\
\hline $\begin{array}{l}\text { Item 4: You are confronted by } \\
\text { a salesman who tries to sell } \\
\text { you something you are not } \\
\text { interested in. }\end{array}$ & $\begin{array}{l}\text { - Walk away } \\
\text { - Politely tell them } \\
\text { you're not } \\
\text { interested } \\
\text { - Ask to be removed } \\
\text { from the list }\end{array}$ & $\begin{array}{l}\text { Don't answer the } \\
\text { door } \\
\text { - Slam the door }\end{array}$ \\
\hline $\begin{array}{l}\text { Item 5: You have let your } \\
\text { home become too cluttered } \\
\text { with items you use } \\
\text { infrequently but which have } \\
\text { much sentimental value for } \\
\text { you. }\end{array}$ & $\begin{array}{l}\text { - } \text { Rent a storage unit } \\
\text { - } \text { Have a yard } \\
\text { sale/garage sale } \\
\text { - Keep the most } \\
\text { sentimental } \\
\text { - } \text { Donate to charity } \\
\text { - } \text { Frame in a shadow } \\
\text { box }\end{array}$ & $\begin{array}{l}\text { - Live with the } \\
\text { clutter }\end{array}$ \\
\hline $\begin{array}{l}\text { Item 6: You wish to spend } \\
\text { more time socializing with } \\
\text { certain friends but are unable } \\
\text { to find a mutually convenient } \\
\text { time when you and they are } \\
\text { both free. }\end{array}$ & $\begin{array}{l}\text { - Set a date well in } \\
\text { to the future when } \\
\text { you can all get } \\
\text { together } \\
\text { - Re-assess my other } \\
\text { activities that } \\
\text { prevent us from } \\
\text { getting together } \\
\text { - Exchange email } \\
\text { for the time being } \\
\text { - Start a new activity } \\
\text { together }\end{array}$ & $\begin{array}{l}\text { - Kidnap them from } \\
\text { work }\end{array}$ \\
\hline
\end{tabular}


Appendix C: Everyday Problem Solving Inventory Guidelines for the Current Study

(Adapted from Denney/Marsiske, 1995)

1. Each solution must specifically address the defined problem. Solutions cannot deal with context or implications of the problem, only the stated problem.

2. Each solution must be able to "stand alone." That is, you should be able to read the problem solution and understand how it addresses the problem. Do not penalize for misspelling, incomplete sentences, or poor linguistic style, however, the solution must communicate/convey enough information to solve the problem. Do not infer/impute information in the problem solution. Do not consider other sources of information (i.e., dyadic partner's protocol), only rate the information explicitly provided by the participant.

3. Consider the quality of the solution when tallying up solutions, including the safety, effectiveness, or plausibility of the solution. (i.e., "Is the person harming themselves or others?")

4. Do not count commentary about the problem, context, or situation, or "words of wisdom" as solutions (e.g., "You should never squander friendship."). This includes reframing or reinterpretation of the problem.

5. Pay attention to punctuation, although a period or comma may not always separate solutions. Solutions don't have to be complete sentences.

6. Separate lines are generally good guidelines for distinction of separate solutions; however, solutions may or may not be separated by lines.

7. Punctuation such as commas, periods, and dashes may indicate separate solutions. Watch punctuation carefully. Do not assume the participant wanted the statements to go together. If statement can stand alone, count them as two separate solutions (e.g., "I would call my friend and apologize).

8. Although numbered solutions are generally useful guidelines, solutions may or may not be numbered.

9. Count each different possible source of help as a separate solution (e.g., Friends, neighbors, family, etc.)

10. Count each individual source of help as a separate solution (e.g., Son, grandson, etc.)

11. Count each method as a separate solution (e.g., telephone, mail, talk in person, etc.)

12. Don't count solutions, which say "Do nothing," "Sleep on it," or "Think it over."

13. Don't count emotions as solutions (e.g., "I would worry"). 
14. Don't count religious convictions as solutions (e.g., "I would put it in God's hands").

15. If someone's solution is just the re-wording of another one, don't count them twice.

16. Count only positive, not negative actions. (e.g., "I wouldn't get mad."). There is an exception to this rule if the negative action does relate to the target problem (e.g., "I would not engage in the gossip.")

17. Count "or" solutions as "and" solutions.

18. Count "and" solutions as separate solutions. (Ex: Call and/or mail the company would be two separate solutions.)

19. Don't count solutions which merely say "do it somehow" but don't say how.

20. Count State, Country, City, and Federal Governments as separate solutions.

21. Count each specific agency as separate solutions (Welfare, Red Cross, Sr. Citizens, etc.).

22. Don't count "get help from an agency" as a separate solution when accompanied by one or more examples of such an agency.

23. When solution states to seek help from the Sr. Center and then lists activities available at the Sr. Center, count it as just one solution; i.e., don't count all the activities listed as solutions separate from going to the center.

24. Count "Ignore" as a solution as it applies to the rules. See coding manual for items where it is acceptable to count ignore (e.g., ignore the friends who are gossiping). 